\title{
Avaliação ambiental da produção de ferro gusa: revisão sistemática da literatura, bibliometria e patentes
}

\section{Adriano Souza Leão ${ }^{1}, *$, Arilma do Carmo Tavares $^{1}$, Henrique Leonardo Maranduba ${ }^{2}$ e Edna dos Santos Almeida $^{1}$}

${ }^{1}$ Centro Universitário SENAI CIMATEC. Avenida Orlando Gomes, 1845. Salvador-BA, Brasil (CEP 41650-010).*E-mail: adrianoleaoeng@outlook.com. ${ }^{2}$ Instituto Federal de Educação, Ciência e Tecnologia da Bahia. Campus Jequié. Loteamento Cidade Nova, S/№. Jequié-BA, Brasil (CEP 45201-570).

Resumo. A siderurgia de ferro e aço tem sofrido pressões e transformações determinantes nos últimos anos em função dos impactos ambientais gerados pelo setor. 0 ferro gusa, principal matéria-prima do aço, é produzido majoritariamente por meio de alto-fornos, uma tecnologia intensiva em consumo de energia, de recursos primários e, também, em emissão de gases de efeito estufa (GEE). Ao passo que o setor se vê pressionado com a escassez de matérias-primas e as repercussões da mudança climática, rotas tecnológicas em processo de desenvolvimento têm indicado uma potencial melhoria no desempenho ambiental do ciclo de vida do ferro gusa. A Avaliação de Ciclo de Vida (ACV) é um método que visa a estimar os impactos ambientais de produtos, serviços e processos, considerando desde a cadeia de suprimentos até a obtenção do produto final, bem como uso, e descarte final. Neste estudo, realizou-se uma revisão sistemática da literatura, análise bibliométrica e de patentes com o objetivo de levantar evidências e investigar as lacunas acerca dos aspectos ambientais da produção de ferro gusa, dos impactos do seu ciclo de vida e das reivindicações de inovação na siderurgia associadas às tecnologias "verdes". Verificou-se uma tendência de crescimento tanto em contribuições científicas quanto em registros de patente na última década, acentuada a partir de 2013. Os tópicos em destaque na discussão acadêmica abrangem desde inventários de fluxos no início da década, até o desempenho ambiental do processo produtivo, nos estudos mais recentes. 0 domínio tecnológico esteve focado na viabilização do reaproveitamento de resíduos, desenvolvimento de materiais alternativos e otimização de processo. Geograficamente, os países asiáticos, sobretudo a China, destacaram-se com a maior quantidade de contribuições acadêmicas e tecnológicas, embora países da Europa, das Américas e a Austrália também tenham se mobilizado ativamente. A convergência observada nesses resultados evidenciou a ocorrência de fenômenos análogos em
Recebido 21/02/2020

Aceito

$26 / 08 / 2020$

Disponível on line

$27 / 08 / 2020$

Publicado

$31 / 08 / 2020$

Acesso aberto

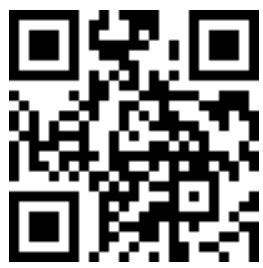

ORCID

(D) 0000-0001-6743-8099 Adriano Souza Leão

(D) 0000-0003-3610-4197 Arilma do Carmo Tavares

(D) 0000-0002-4358-5366 Henrique Leonardo Maranduba

ISSN 2359-1412/RBGAS-2020-0026/2020/7/16/29/905

Rev. Bras. Gest. Amb. Sustent.

http://revista.ecogestaobrasil.net 
diferentes perspectivas de produção de conhecimento: academia e indústria. Por fim, o tema revela ainda possuir potencial de aprofundamento, especialmente com respeito aos fornos em desenvolvimento.

Palavras-chave: Pensamento do Ciclo de Vida (PCV); Ecologia Industrial; Tecnologia emergente; Pegada de carbono; Eficiência energética.

Abstract. Environmental assessment of pig iron production: Systematic review of literature, bibliometrics and patents. The iron and steel industry has undergone significant pressures and transformations in recent years due to the environmental impacts caused by the sector. Pig iron, the main raw material of steel, is predominantly produced by blast furnaces, a technology that is intensive in energy use, primary resource consumption as well as greenhouse gas (GHG) emission. While the sector is pressured by the scarcity of raw materials and the repercussions of climate change, technological routes in development process have pointed to a potential for a better environmental performance of the pig iron life cycle. The Life Cycle Assessment (LCA) is a method that aims to estimate the environmental impacts of products, services and processes, considering from the supply chain to the final product, as well as use, and final disposal. In this study, a systematic review of literature, bibliometric and patent analysis were conducted to collect evidence and investigate the gaps concerning the environmental aspects of pig iron production, the impacts of its life cycle and the claims of innovation in the steel industry associated with "green" technologies. There has been an upward trend in both scientific contributions and patent registrations over the past decade, intensified since 2013. The topics highlighted in the academic discussion range from flow inventories at the beginning of the decade to the environmental performance of the manufacture process, in the most recent studies. The technological domain was focused on the viability of waste reuse, development of alternative materials and process optimization. Geographically, Asian countries, especially China, stood out with the highest number of academic and technological contributions, although countries in Europe, the Americas and Australia also have actively mobilized. The convergence observed in these results showed the occurrence of similar phenomena in different perspectives of knowledge production: academia and industry. Finally, the theme reveals still potential for further development, especially with regard to developing furnaces.

Keywords: Life Cycle Thinking (LCT); Industrial Ecology; Emerging technology; Carbon footprint; Energy efficiency.
0000-0001-5111-062X

Edna dos Santos

Almeida 


\section{Introdução}

O ferro gusa, ou simplesmente gusa, é o produto resultante da redução de minério de ferro por um agente redutor carbonoso, também fonte de energia do processo (IIMA, 2018). Essa redução se processa em fornos industriais com auxílio de fluxantes e outros materiais. Os altos-fornos produzem 94\% do ferro gusa no mundo (CGEE, 2010; Smil, 2016).

A maior parte, cerca de $70 \%$, é consumida na produção de aço. A composição mássica típica do ferro gusa possui pelo menos 92\% de ferro (Fe), 3,5\%-4,5\% de carbono $(\mathrm{C})$, podendo conter silício $(\mathrm{Si})$, enxofre $(\mathrm{S})$, fósforo $(\mathrm{P})$ e manganês $(\mathrm{Mn})$ como impurezas (IIMA, 2018).

De acordo com o Relatório Estatístico Anual da Associação Mundial de Aço (WSA, 2018), em 2017, a produção mundial de ferro gusa foi da ordem de 1,2 trilhões de toneladas. A China foi o país com maior produção, cerca de 61,4\% desse total. Em sexto lugar, o Brasil com 2,4\%. Segundo o Anuário Estatístico do Setor Metalúrgico (MME, 2018), 32,1 milhões de toneladas foram produzidas no Brasil, sendo 72,6\% em Minas Gerais, $14,5 \%$ no Maranhão e Pará juntos, 9,1\% no Espírito Santo e 3,8\% no Mato Grosso do Sul.

A adoção de medidas mitigadoras de impacto devido à pressão externa pode favorecer perenidade no setor produtivo brasileiro (Wickboldt et al., 2018). Diante do cenário global de mudanças no mercado de matérias-primas, alternativas economicamente sustentáveis para siderurgia tem sido desenvolvidas (Gordon et al., 2015). Em face à pressão das mudanças climáticas na siderurgia, a redução do consumo de energia, bem como das emissões de Gases de Efeito Estufa (GEE) estão na agenda.

A produção de ferro e aço está entre as mais intensivas em uso de energia e corresponde à maior parcela de emissão de $\mathrm{CO}_{2}$ do setor manufatureiro, aproximadamente $27 \%$ (Hasanbeigi et al., 2013). Os autores citam que já há tecnologias de baixo consumo energético e emissões aplicáveis à siderurgia em estado de comercialização. Todavia, a informação sobre as tecnologias ainda não comercializadas é limitada.

De acordo com relatório do Centro de Gestão e Estudos Estratégicos (CGEE, 2010), na discussão acerca do "desenvolvimento sustentável" no setor siderúrgico brasileiro são preocupações centrais, dentre outras, a normalização cada vez mais restritiva no tocante à exploração de recursos naturais e fortalecimento das ações das organizações ambientais. Estrategicamente, o setor caminha para articular-se aderindo à programas ambientais e metas de redução de GEE voluntários.

Recentemente, os mais novos altos-fornos tem sido aprimorados com foco nas matérias-primas de carregamento e injeção de combustíveis auxiliares (Smil, 2016). Isso pode tornar o processo mais fluido, aumentando produtividade e, ao mesmo tempo, reduzindo a demanda de agentes redutores. 0 potencial de uso de briquetes se apresenta como alternativa para explorar resíduos de ferro e carbono no processo em novos fornos. Além disso, a reestruturação da matriz energética do setor, priorizando fontes renováveis, também é uma medida relevante para o avanço em ecologia industrial.

Ademais, aspectos operacionais relevantes como gestão da cadeia logística, dos resíduos e do uso da água para uma indústria mais verde, isto é, mais ecológica e sustentável, podem ser citados. 0 entendimento das etapas desde a concepção até o final da vida útil de um produto é crucial para a gestão dos impactos ambientais que ele provoca direta ou indiretamente antes, durante e após sua produção. Isso fornece bases objetivas para evitar que a solução de um problema ambiental acabe gerando outros (IBICT, 2014).

Uma das ferramentas de análise ambiental de produtos e serviços da indústria é a Avaliação do Ciclo de Vida (ACV), metodologia internacionalmente reconhecida (ABNT,

Rev. Bras. Gest. Amb. Sustent., 2020, vol. 7, n. 16, p. 905-936. 
2006). O método consiste em compilar as entradas e saídas de recursos materiais e energéticos do início ao final da vida de um sistema de produto e estimar os impactos produzidos sobre o meio ambiente em cada etapa (IBICT, 2014). Em virtude da sua padronização, é possível estabelecer comparações entre os sistemas produtivos (benchmarking ecológico).

Diante do exposto, este trabalho se propôs a realizar uma revisão sistemática da literatura, análise bibliométrica e de patentes para levantar evidências e identificar lacunas a respeito dos aspectos ambientais da obtenção de ferro gusa, da aplicação da ACV para estimar seus impactos e das contribuições tecnológicas com viés ecológico materializadas pela indústria siderúrgica.

\section{Metodologia}

A estratégia usada para realizar a revisão sistemática foi buscar trabalhos em repositórios científicos concernentes ao tema e selecionar os manuscritos mais relevantes para posterior análise e discussão de seus principais aspectos e constatações (Figura 1).

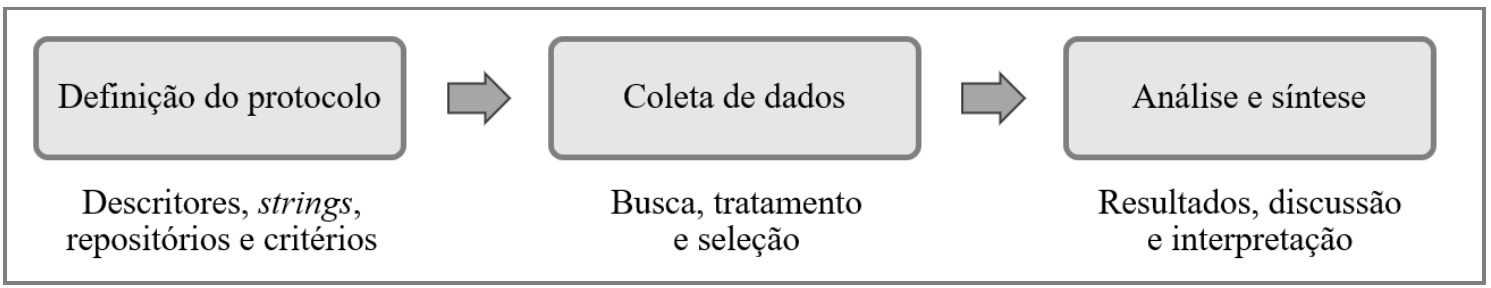

Figura 1. Esquema adotado para cada seção da revisão.

As ações foram realizadas na seguinte sequência: sistematização de questões de pesquisa; definição dos descritores e período/ano de publicação; filtragem de trabalhos após leitura de título e resumo; seleção após leitura completa dos manuscritos disponíveis; identificação dos achados que respondem parcial ou totalmente às perguntas; e, por fim, análise crítica das publicações remanescentes.

O problema de pesquisa foi sistematizado em uma questão central (Q1) e em duas outras questões complementares (Q2 e Q3) para melhor delimitação do problema, oriundas da contextualização da fundamentação teórica, como segue:

Q1. Existem trabalhos que aplicaram a ACV para avaliar o perfil ambiental do ferro gusa produzido por pelo menos uma rota/tecnologia?

Q2. Existem trabalhos que estimaram a pegada de carbono da produção de ferro gusa?

Q3. Existem trabalhos que estimaram a demanda acumulada de energia da produção de ferro gusa?

As questões complementares remetem não apenas aos impactos operacionais do ciclo de vida produtivo, como emissões diretas e eficiência energética na etapa de manufatura/produção dentro da usina, mas também, em uma perspectiva mais abrangente, às etapas pré-operacionais - pegada de carbono e demanda acumulada de energia. 
Essas últimas são categorias de impacto da ACV que compreendem contribuições desde a extração de matérias-primas, pré-manufatura dos principais insumos demandados no processo, até o portão de entrada da usina. Podem ainda refletir etapas pós-operacionais, função da extensão das fronteiras em análise.

Pesos foram atribuídos para cada questão em função da aderência do manuscrito. No caso de resposta completa à questão Q1, a publicação recebe nota 5,0, e resposta parcial, nota 2,5. Para Q2, total 3,0 e parcial 1,5. E para Q3, total 2,0 e parcial 1,0. Um manuscrito pode atingir a nota máxima de 10 , sendo que quanto mais aderente o conteúdo do trabalho, mais sua nota se aproxima desse limite máximo.

Sinônimos e termos alternativos foram considerados como em "ferro gusa" e "siderurgia". Da mesma forma, acrônimos/abreviaturas como em "ACV" e "Avaliação de Ciclo de Vida". Além desses, o asterisco $\left(^{*}\right)$ para contemplar diferentes sufixos, como em "ambient*" que é interpretado pelos mecanismos de busca como o conjunto "ambiente", "ambiental", "ambientais" e outros. Foram usados os descritores a seguir:

- Ferro gusa, Siderurgia, ACV, Avaliação de Ciclo de Vida, Eficiência energética, Carbono, Ambiental;

- Pig iron, Ironmaking, LCA, Life Cycle Assessment, Energy efficiency, Carbon, Environmental.

A string foi montada contendo três elementos principais separados pelo booleano "AND". O primeiro é composto pelos descritores referentes ao objeto de estudo ("ferro gusa" OR siderurgi*). 0 segundo, pelo método científico de análise de impacto ambiental (acv OR "avaliação de ciclo de vida").

E o terceiro elemento é formado pelos termos auxiliares ("eficiência energética" OR carbon* OR ambient*). Descritores do objeto de estudo e do método são referentes à questão principal (Q1) e os auxiliares, às complementares (Q2 e Q3). O mesmo procedimento foi feito com os descritores em inglês.

A busca foi realizada nos repositórios Web of Science, Science Direct, Scopus e Scielo, bem como no Scholar Google, uma ferramenta de busca que acessa repositórios científicos indexáveis. 0 período considerado para o estado da arte foram os últimos 3 anos e o ano corrente, de 2016 a 2019. Publicações relevantes dos anos anteriores, de 2000 a 2015, também foram consideradas. Os critérios de inclusão que geram exclusão dos trabalhos não aderentes foram aplicados na seguinte ordem:

- Descritores contidos no título, resumo e/ou palavras-chave;

- Título, resumo e palavras-chave aderentes ao tema;

- Acesso ao documento completo (visualização ou download);

- Metodologia, resultados, discussão e conclusões aderentes às questões;

- Confronto com as questões de pesquisa e atribuição dos pesos.

Após isso, os trabalhos remanescentes de todo o processo de seleção foram analisados um a um, com destaque para os de maior nota, elencando seus principais aspectos, contribuições e lacunas tendo em vista o objetivo desta pesquisa.

Análise e síntese. As buscas foram realizadas no dia 5 de agosto de 2019. Foram encontrados 142 registros. A Tabela 1 mostra a quantidade de publicações recuperadas em cada repositório na primeira busca utilizando termos em inglês e português para 0 período considerado o estado da arte e também para o anterior. 
Tabela 1. Primeira etapa: quantidade de trabalhos encontrada nas buscas.

\begin{tabular}{lcccccc}
\hline \multirow{2}{*}{ Repositório } & \multicolumn{7}{c}{ Com descritores em inglês/português } \\
\cline { 2 - 7 } & $\mathbf{2 0 1 9}$ & $\mathbf{2 0 1 8}$ & $\mathbf{2 0 1 7}$ & $\mathbf{2 0 1 6}$ & $\mathbf{2 0 0 0 - 2 0 1 5}$ & Total \\
\hline Scholar Google & $6 / 0$ & $9 / 3$ & $7 / 4$ & $9 / 2$ & $33 / 15$ & 88 \\
Scopus & $0 / 0$ & $2 / 0$ & $0 / 0$ & $1 / 0$ & $21 / 0$ & 24 \\
Web of Science & $0 / 0$ & $2 / 0$ & $0 / 0$ & $1 / 0$ & $19 / 0$ & 22 \\
Science Direct & $0 / 0$ & $1 / 0$ & $0 / 0$ & $0 / 0$ & $7 / 0$ & 8 \\
Scielo & $0 / 0$ & $0 / 0$ & $0 / 0$ & $0 / 0$ & $0 / 0$ & 0 \\
\hline
\end{tabular}

Notou-se que a maioria dos manuscritos foi encontrada no Scholar Google (62\%). Já Scopus, Web of Science e Science Direct correspondem a 38\% dos achados na primeira etapa. No Scielo, nenhum trabalho foi recuperado. A Tabela 2 apresenta os resultados após verificação e seleção por título, resumo e palavras-chave.

Tabela 2. Segunda etapa: quantidade de trabalhos remanescente após leitura de título, resumo e palavras-chave.

\begin{tabular}{|c|c|c|c|c|c|c|c|c|}
\hline \multirow{2}{*}{ Repositório } & \multicolumn{6}{|c|}{ Com descritores em inglês/português } & \multirow{2}{*}{$\begin{array}{l}\text { Indispo- } \\
\text { níveis }\end{array}$} & \multirow{2}{*}{$\begin{array}{l}\text { Dupli- } \\
\text { cados }\end{array}$} \\
\hline & 2019 & 2018 & 2017 & 2016 & $2000-2015$ & Total & & \\
\hline Scholar Google & $2 / 0$ & $4 / 0$ & $5 / 0$ & $5 / 0$ & $9 / 2$ & 27 & 6 & \multirow{5}{*}{17} \\
\hline Scopus & $0 / 0$ & $0 / 0$ & $0 / 0$ & $0 / 0$ & $14 / 0$ & 14 & 1 & \\
\hline Web of Science & $0 / 0$ & $0 / 0$ & $0 / 0$ & $0 / 0$ & $16 / 0$ & 16 & 1 & \\
\hline Science Direct & $0 / 0$ & $0 / 0$ & $0 / 0$ & $0 / 0$ & $6 / 0$ & 6 & 0 & \\
\hline Scielo & $0 / 0$ & $0 / 0$ & $0 / 0$ & $0 / 0$ & $0 / 0$ & 0 & 0 & \\
\hline
\end{tabular}

Dos 71 trabalhos selecionados, oito não estavam disponíveis para leitura completa e 17 eram duplicados, isto é, encontrados em mais de um repositório (Figura 2). Um dos achados é um livro, de onde dois capítulos foram selecionados. Isso resultou em uma soma de 47 trabalhos diferentes para serem avaliados, incluindo artigos de periódico, artigos de congresso, capítulos de livro, dissertações, teses e relatórios técnicos.

Uma quantidade substancial de publicações duplicadas (94\%) foi encontrado entre os repositórios Scopus, Web of Science e Science Direct. Já o Google Scholar, apesar de seu mecanismo de busca ser menos seletivo, apenas 1 trabalho era duplicado em relação às outras bases. Embora tenha sido o repositório com maior quantidade de trabalhos recuperados até esta etapa, $22 \%$ não estavam disponíveis para visualização ou download.

Na terceira etapa, publicações com visualização ou download permitido dentro do VPN concedido ao SENAI CIMATEC pela CAPES foram analisadas, permanecendo apenas aquelas consideradas com contribuição/conteúdo que respondesse no mínimo parcialmente pelo menos uma das questões de pesquisa, sendo pontuadas de acordo. 


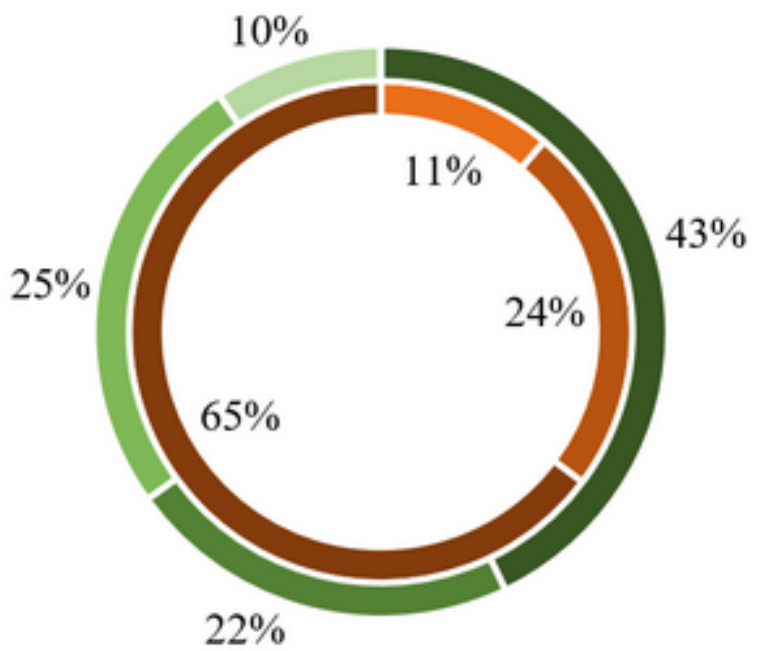

- Scholar Google

- Scopus

- Web of Science

- Science Direct

Scielo

- Indisponíveis

- Duplicados

- Remanescentes

Figura 2. Amostra de trabalhos selecionados até a segunda etapa por repositório e por disponibilidade.

A Tabela 3 apresenta informação completa (metadados) dos 36 manuscritos retidos após a terceira etapa, classificadas em ordem cronológica decrescente atribuindo um número de 1 a 36 associado à letra "P" de publicação. A Tabela 4 traz uma análise da contribuição e do conteúdo desses trabalhos resultantes, utilizada para pontuá-los em confronto com as questões norteadoras.

Tabela 3. Terceira etapa: trabalhos selecionados após leitura completa das publicações disponíveis.

\begin{tabular}{|c|c|c|c|c|c|}
\hline $\mathbf{P}$ & Autoria & Ano & Título & \begin{tabular}{|l|} 
País do \\
1 o autor \\
\end{tabular} & \begin{tabular}{|l|} 
Tipo de \\
publicação
\end{tabular} \\
\hline P1 & Lv et al. & 2019 & $\begin{array}{l}\text { Life cycle energy consumption and } \\
\text { greenhouse gas emissions of iron pelletizing } \\
\text { process in China, a case study }\end{array}$ & China & $\begin{array}{l}\text { Artigo de } \\
\text { periódico }\end{array}$ \\
\hline P2 & Suopajärvi et al. & 2018 & $\begin{array}{l}\text { Use of biomass in integrated steelmaking: } \\
\text { Status quo, future needs and comparison to } \\
\text { other low- } \mathrm{CO}_{2} \text { steel production technologies }\end{array}$ & Finlândia & $\begin{array}{l}\text { Artigo de } \\
\text { periódico }\end{array}$ \\
\hline P3 & Chowdhury et al. & 2018 & $\begin{array}{l}\text { Reducing industrial energy demand in the } \\
\text { UK: A review of energy efficiency } \\
\text { technologies and energy saving potential in } \\
\text { selected sectors }\end{array}$ & Inglaterra & $\begin{array}{l}\text { Artigo de } \\
\text { periódico }\end{array}$ \\
\hline P4 & Ma et al. & 2018 & $\begin{array}{l}\text { An evaluation of input-output value for } \\
\text { sustainability in a chinese steel production } \\
\text { system based on emergy analysis }\end{array}$ & China & $\begin{array}{l}\text { Artigo de } \\
\text { periódico }\end{array}$ \\
\hline P5 & Miah & 2018 & $\begin{array}{l}\text { Use of waste resources in the sinter plant in } \\
\text { ironmaking }\end{array}$ & Inglaterra & Tese \\
\hline P6 & Suopajarvi et al. & 2017 & $\begin{array}{l}\text { Extensive review of the opportunities to use } \\
\text { biomass-based fuels in iron and steelmaking } \\
\text { processes }\end{array}$ & Finlândia & $\begin{array}{l}\text { Artigo de } \\
\text { periódico }\end{array}$ \\
\hline P7 & Shatokha et al. & 2017 & $\begin{array}{l}\text { Trends and factors of sustainable } \\
\text { development: Iron and Steelmaking }\end{array}$ & Ucrânia & \begin{tabular}{|l|} 
Capítulo \\
livro
\end{tabular} \\
\hline
\end{tabular}

Rev. Bras. Gest. Amb. Sustent., 2020, vol. 7, n. 16, p. 905-936. 
Tabela 3. Continuação.

\begin{tabular}{|c|c|c|c|c|c|}
\hline $\mathbf{P}$ & Autoria & Ano & Título & $\begin{array}{l}\text { País do } \\
\text { 1o autor }\end{array}$ & \begin{tabular}{|l|} 
Tipo de \\
publicação
\end{tabular} \\
\hline P8 & Shatokha & 2017 & $\begin{array}{l}\text { Technologies for sustainable development: } \\
\text { best available and breakthrough }\end{array}$ & Ucrânia & $\begin{array}{l}\text { Capítulo } \\
\text { livro }\end{array}$ \\
\hline P9 & $\begin{array}{l}\text { Rojas-Cardenas } \\
\text { et al. }\end{array}$ & 2017 & $\begin{array}{l}\text { Energy efficiency in the Mexican iron and } \\
\text { steel industry from an international } \\
\text { perspective }\end{array}$ & México & $\begin{array}{l}\text { Artigo de } \\
\text { periódico }\end{array}$ \\
\hline P10 & Bains et al. & 2017 & $\mathrm{CO}_{2}$ capture from the industry sector & EUA & $\begin{array}{l}\text { Artigo de } \\
\text { periódico }\end{array}$ \\
\hline P11 & Mousa et al. & 2016 & $\begin{array}{l}\text { Biomass applications in iron and steel } \\
\text { industry: An overview of challenges and } \\
\text { opportunities }\end{array}$ & Suécia & $\begin{array}{l}\text { Artigo de } \\
\text { periódico }\end{array}$ \\
\hline P12 & Pan et al. & 2016 & $\begin{array}{l}\text { Sustainability evaluation of a steel } \\
\text { production system in China based on } \\
\text { emergy }\end{array}$ & China & $\begin{array}{l}\text { Artigo de } \\
\text { periódico }\end{array}$ \\
\hline P13 & Wu et al. & 2016 & $\begin{array}{l}\text { Integrated assessment of exergy, energy and } \\
\text { carbon dioxide emissions in an iron and } \\
\text { steel industrial network }\end{array}$ & China & $\begin{array}{l}\text { Artigo de } \\
\text { periódico }\end{array}$ \\
\hline P14 & Olmez et al. & 2016 & $\begin{array}{l}\text { The environmental impacts of iron and steel } \\
\text { industry: A life cycle assessment study }\end{array}$ & Turquia & $\begin{array}{l}\text { Artigo de } \\
\text { periódico }\end{array}$ \\
\hline P15 & Bahadir & 2016 & $\begin{array}{l}\text { Analysis of the environmental effects of } \\
\text { international outsourcing: Study of the iron } \\
\text { casting industry }\end{array}$ & EUA & $\begin{array}{l}\text { Artigo de } \\
\text { periódico }\end{array}$ \\
\hline P16 & Saade et al. & 2015 & $\begin{array}{l}\text { Appropriateness of environmental impact } \\
\text { distribution methods to model blast furnace } \\
\text { slag recycling in cement making }\end{array}$ & Brasil & $\begin{array}{l}\text { Artigo de } \\
\text { periódico }\end{array}$ \\
\hline P17 & Reuter et al. & 2015 & $\begin{array}{l}\text { Simulation-based design for resource } \\
\text { efficiency of metal production and recycling } \\
\text { systems: Cases-copper production and } \\
\text { recycling, e-waste (LED lamps) and nickel } \\
\text { pig iron }\end{array}$ & Finlândia & $\begin{array}{l}\text { Artigo de } \\
\text { periódico }\end{array}$ \\
\hline P18 & Jahanshahi et al. & 2015 & $\begin{array}{l}\text { Development of low-emission integrated } \\
\text { steelmaking process }\end{array}$ & Austrália & $\begin{array}{l}\text { Artigo de } \\
\text { periódico }\end{array}$ \\
\hline P19 & Crossin & 2015 & $\begin{array}{l}\text { The greenhouse gas implications of using } \\
\text { ground granulated blast furnace slag as a } \\
\text { cement substitute }\end{array}$ & Austrália & $\begin{array}{l}\text { Artigo de } \\
\text { periódico }\end{array}$ \\
\hline P20 & Chen et al. & 2015 & $\begin{array}{l}\text { Life cycle assessment of the comprehensive } \\
\text { utilisation of vanadium titano-magnetite }\end{array}$ & China & $\begin{array}{l}\text { Artigo de } \\
\text { periódico }\end{array}$ \\
\hline P21 & Arasto & 2015 & $\begin{array}{l}\text { Techno-economic evaluation of significant } \\
\mathrm{CO}_{2} \text { emission reductions in the iron and } \\
\text { steel industry with CCS }\end{array}$ & Finlândia & Tese \\
\hline P22 & Fick et al. & 2014 & $\begin{array}{l}\text { Using biomass for pig iron production: A } \\
\text { technical, environmental and economical } \\
\text { assessment }\end{array}$ & França & $\begin{array}{l}\text { Artigo de } \\
\text { periódico }\end{array}$ \\
\hline P23 & Suopajärvi et al. & 2014 & $\begin{array}{l}\text { Bioreducer use in Finnish blast furnace } \\
\text { ironmaking: Analysis of } \mathrm{CO}_{2} \text { emission } \\
\text { reduction potential and mitigation cost }\end{array}$ & Finlândia & $\begin{array}{l}\text { Artigo de } \\
\text { periódico }\end{array}$ \\
\hline P24 & Vadenbo et al. & 2013 & $\begin{array}{l}\text { Life cycle assessment model for the use of } \\
\text { alternative resources in ironmaking }\end{array}$ & Suíça & $\begin{array}{l}\text { Artigo de } \\
\text { periódico }\end{array}$ \\
\hline P25 & Choi & 2013 & $\begin{array}{l}\text { Hybrid life cycle assessment of steel } \\
\text { production with carbon capture and storage }\end{array}$ & Noruega & Dissertação \\
\hline
\end{tabular}


Tabela 3. Continuação.

\begin{tabular}{|c|c|c|c|c|c|}
\hline $\mathbf{P}$ & Autoria & Ano & Título & $\begin{array}{l}\text { País do } \\
\text { 10 autor }\end{array}$ & \begin{tabular}{|l|} 
Tipo de \\
publicação
\end{tabular} \\
\hline P26 & Saade & 2013 & $\begin{array}{l}\text { Influência da alocação de impactos na } \\
\text { indústria siderúrgica sobre a avaliação de } \\
\text { ciclo de vida de cimentos }\end{array}$ & Brasil & Dissertação \\
\hline P27 & Burchart-Korol & 2013 & $\begin{array}{l}\text { Life cycle assessment of steel production in } \\
\text { Poland: a case study }\end{array}$ & Polônia & $\begin{array}{l}\text { Artigo de } \\
\text { periódico }\end{array}$ \\
\hline P28 & Fick et al. & 2012 & $\begin{array}{l}\text { Environmental assessment of biomass } \\
\text { options for iron making }\end{array}$ & França & $\begin{array}{l}\text { Artigo de } \\
\text { congresso }\end{array}$ \\
\hline P29 & Burchart-Korol & 2012 & $\begin{array}{l}\text { Fossil fuels consumption evaluation in blast } \\
\text { furnace technology based on different life } \\
\text { cycle impact assessment methods }\end{array}$ & Polônia & $\begin{array}{l}\text { Artigo de } \\
\text { congresso }\end{array}$ \\
\hline P30 & Ding e Li & 2011 & $\begin{array}{l}\text { Environmental benefit from blast furnace } \\
\text { gas recycling in the integrated steelworks }\end{array}$ & China & $\begin{array}{l}\text { Artigo de } \\
\text { congresso }\end{array}$ \\
\hline P31 & Kuramochi & 2011 & $\begin{array}{l}\mathrm{CO}_{2} \text { capture in industries and distributed } \\
\text { energy systems: Possibilities and limitations }\end{array}$ & Japão & Tese \\
\hline P32 & Ramos & 2011 & $\begin{array}{l}\text { Drivers and barriers to industrial energy } \\
\text { efficiency and climate change mitigation in } \\
\text { Mexico-the case of the iron and steel } \\
\text { industry }\end{array}$ & Inglaterra & Tese \\
\hline P33 & $\begin{array}{l}\text { Norgate e } \\
\text { Langberg }\end{array}$ & 2009 & $\begin{array}{l}\text { Environmental and economic aspects of } \\
\text { charcoal use in steelmaking }\end{array}$ & Austrália & $\begin{array}{l}\text { Artigo de } \\
\text { periódico }\end{array}$ \\
\hline P34 & Sablowski & 2008 & $\begin{array}{l}\text { Balanço de materiais na gestão ambiental da } \\
\text { cadeia produtiva do carvão vegetal para } \\
\text { produção de ferro gusa em Minas Gerais }\end{array}$ & Brasil & Tese \\
\hline P35 & Ryman & 2007 & $\begin{array}{l}\text { Evaluation of energy and } \mathrm{CO}_{2} \text { emission } \\
\text { strategies in blast furnace ironmaking and } \\
\text { oxygen steelmaking }\end{array}$ & Suécia & Dissertação \\
\hline P36 & $\begin{array}{l}\text { Gielen e } \\
\text { Moriguchi }\end{array}$ & 2001 & $\begin{array}{l}\text { Environmental strategy design for the } \\
\text { Japanese iron and steel industry: A Global } \\
\text { perspective }\end{array}$ & Japão & $\begin{array}{l}\text { Relat. } \\
\text { técnico }\end{array}$ \\
\hline
\end{tabular}

Tabela 4. Análise da contribuição/conteúdo das publicações remanescentes da terceira etapa, confronto das questões norteadoras e pontuação.

\begin{tabular}{|l|l|l|l|l|l|}
\hline P & Contribuição / conteúdo & \multicolumn{2}{|l|}{ Pergunta } & \multicolumn{2}{|l|}{ Resposta } \\
\cline { 2 - 6 } & $\begin{array}{l}\text { Calcula a intensidade energética e emissões de GHG da } \\
\text { peletização de ferro na China, sendo a pelota uma das matérias- } \\
\text { primas mais comuns para suprir a demanda de ferro do } \\
\text { processo de produção do gusa. }\end{array}$ & $\begin{array}{l}\text { To- } \\
\text { tal }\end{array}$ & $\begin{array}{l}\text { Par- } \\
\text { cial }\end{array}$ & Nota \\
\hline P2 & $\begin{array}{l}\text { Analisa a aplicação de biomassa como fonte redutora e de } \\
\text { combustível do processo produtivo do produto final, o aço, } \\
\text { inclui a produção de ferro gusa como principal matéria-prima } \\
\text { do aço. No decorrer da análise, compara o conteúdo e as } \\
\text { emissões de carbono das diversas fontes de biomassa com } \\
\text { outros combustíveis usuais como carvão mineral e outros } \\
\text { biocombustíveis. }\end{array}$ & $\mathrm{x}$ & $\mathrm{x}$ & 2,5 \\
\hline
\end{tabular}


Tabela 4. Continuação.

\begin{tabular}{|c|c|c|c|c|c|c|c|}
\hline \multirow[b]{2}{*}{$\mathbf{P}$} & \multirow[b]{2}{*}{ Contribuição / conteúdo } & \multicolumn{3}{|c|}{ Pergunta } & \multicolumn{2}{|c|}{ Resposta } & \multirow[b]{2}{*}{ Nota } \\
\hline & & Q1 & Q2 & Q3 & $\begin{array}{l}\text { To- } \\
\text { tal }\end{array}$ & $\begin{array}{l}\text { Par- } \\
\text { cial }\end{array}$ & \\
\hline P3 & $\begin{array}{l}\text { Discute de uma gama de serviços industriais, suas } \\
\text { oportunidades e potencial de redução na demanda de energia e } \\
\text { consequente mitigação de emissões de GEE. No setor } \\
\text { siderúrgico, foca na produção de aço e cadeia de insumos, o que } \\
\text { inclui a produção de gusa e seus insumos. São analisadas redes } \\
\text { de vapor, recuperação de calor e uso de biogás e biomassa. }\end{array}$ & & & $x$ & & $\mathrm{x}$ & 1,0 \\
\hline $\mathrm{P} 4$ & $\begin{array}{l}\text { Analisa o balanço de emergia (energia solar equivalente) da } \\
\text { produção de aço e, consequentemente, de gusa como seu } \\
\text { insumo. Na estimativa dessa grandeza energética, foram } \\
\text { considerados os principais insumos para produzir gusa, os } \\
\text { resíduos formado no processo e emissões (SOx, NOx e } \\
\text { particulado), todos convertidos em emergia equivalente. }\end{array}$ & & & $x$ & & $\mathrm{x}$ & 1,0 \\
\hline P5 & $\begin{array}{l}\text { Estuda diferentes tipos de biomassa como substituta de } 5 \% \text { e } \\
15 \% \text { das fontes carbono na sinterização para redução de } \\
\text { impacto no ciclo de vida da produção de ferro e aço. Na } \\
\text { avaliação de ciclo de vida dos cenários de substituição, as } \\
\text { categorias de pegada de carbono, energia acumulada e depleção } \\
\text { de recursos abióticos. }\end{array}$ & $x$ & $\mathrm{x}$ & $x$ & & $\mathrm{x}$ & 5 \\
\hline P6 & $\begin{array}{l}\text { Revisa as oportunidades de uso de biomassa como } \\
\text { combustível/agente redutor do processo de produção de aço. } \\
\text { Seus resultados mostram que a substituição do carvão vegetal } \\
\text { na produção de gusa traz benefício significativos, inclusive na } \\
\text { redução de emissões de GEE. }\end{array}$ & & $x$ & & & $\mathrm{x}$ & 1,5 \\
\hline P7 & $\begin{array}{l}\text { Fala da eficiência energética e pegada de carbono do setor da } \\
\text { siderurgia. Apresenta resultados de diferentes e mais } \\
\text { avançadas rotas de obtenção de aço para aquele ano. }\end{array}$ & & $x$ & $x$ & & $\mathrm{x}$ & 2,5 \\
\hline P8 & $\begin{array}{l}\text { Trata das tecnologias mais avançadas de produção de ferro e } \\
\text { aço, em uma perspectiva de potencial de aumento da eficiência } \\
\text { energética no setor em vários países. Faz uma revisão dos } \\
\text { programas, projetos e tecnologias de maior relevância nesses } \\
\text { dois aspectos nos dias em curso. }\end{array}$ & & $x$ & $x$ & & $\mathrm{x}$ & 2,5 \\
\hline P9 & $\begin{array}{l}\text { Estima a eficiência energética do setor siderúrgico de ferro e } \\
\text { aço no México, donde a energia foi calculada com base nos } \\
\text { combustíveis e na eletricidade usados no processo. A estimativa } \\
\text { da emissão de gases foi baseada em fatores de conversão do } \\
\text { relatório do IPCC (2006) para cada combustível. }\end{array}$ & & $\mathrm{x}$ & $x$ & & $\mathrm{x}$ & 2,5 \\
\hline P10 & $\begin{array}{l}\text { Estima as emissões e possibilidades de captura de } \mathrm{CO}_{2} \text { em uma } \\
\text { série de setores da indústria química, petroquímica e } \\
\text { siderúrgica em todo o país americano. } \mathrm{Na} \text { produção de ferro e } \\
\text { aço, estimaram as emissões diretas de } \mathrm{CO}_{2} \text {, constataram que a } \\
\text { produção de gusa é o contribuidor principal e que é uma tarefa } \\
\text { difícil extrair o } \mathrm{CO}_{2} \text { do gás de topo para evitar emissões. }\end{array}$ & & $x$ & & & $\mathrm{x}$ & 1,5 \\
\hline P11 & $\begin{array}{l}\text { Revisa as possibilidades de uso de biomassa na siderurgia. Os } \\
\text { pontos críticos do processo identificados foram coqueificação, } \\
\text { sinterização e alto-forno. O primeiro ainda mostra desafios para } \\
\text { uma substituição parcial eficiente de biomassa, na produção de } \\
\text { sínter essa intervenção aponta para redução de emissões } \\
\text { significativa }\left(\mathrm{CO}_{2} \text {, além de SOx e NOx) e na produção de gusa }\right. \\
\text { aponta potencial de mitigação de emissão de carbono fóssil. }\end{array}$ & & $x$ & $x$ & & $\mathrm{x}$ & 2,5 \\
\hline
\end{tabular}


Tabela 4. Continuação.

\begin{tabular}{|c|c|c|c|c|c|c|c|}
\hline \multirow[b]{2}{*}{$\mathbf{P}$} & \multirow[b]{2}{*}{ Contribuição / conteúdo } & \multicolumn{3}{|c|}{ Pergunta } & \multicolumn{2}{|c|}{ Resposta } & \multirow[b]{2}{*}{ Nota } \\
\hline & & Q1 & Q2 & Q3 & $\begin{array}{l}\text { To- } \\
\text { tal }\end{array}$ & $\begin{array}{l}\text { Par- } \\
\text { cial }\end{array}$ & \\
\hline P12 & $\begin{array}{l}\text { Estima o impacto de emissões para atmosfera e para água da } \\
\text { produção de aço através de análise de emergia, danos à saúde } \\
\text { humana e potencial de extinção de espécies. }\end{array}$ & & & $\mathrm{x}$ & & $\mathrm{x}$ & 1,0 \\
\hline P13 & $\begin{array}{l}\text { Calcula o balanço de energia e exergia, bem como emissão de } \\
\mathrm{CO}_{2} \text { da produção de gusa e do aço. Os autores defendem que } \\
\text { pode haver melhorias significativas nesses indicadores a partir } \\
\text { de uma reestruturação das fontes de energia do processo, na } \\
\text { substituição por renováveis e resíduos siderúrgicos (desde pó } \\
\text { de balão, a escórias, sucatas e outros). }\end{array}$ & & $x$ & $\mathrm{x}$ & & $\mathrm{x}$ & 2,5 \\
\hline P14 & $\begin{array}{l}\text { Avalia o ciclo de vida com ACV de berço-ao-portão de sínter, } \\
\text { coque, gusa de alto-forno, aço e produtos acabados de aço. } \\
\text { Considera uma série de categoria de impacto dentro do método } \\
\text { Impact } 2002+\text {, incluindo pegada de carbono. Embora o método } \\
\text { não contenha um indicador de energia acumulada, } \\
\text { considerações sobre consumo de energia de diversas naturezas } \\
\text { e fontes foram feitas em inventário. }\end{array}$ & $\mathrm{x}$ & $\mathrm{x}$ & & $\mathrm{x}$ & & 8,0 \\
\hline P15 & $\begin{array}{l}\text { Avalia o comércio internacional de uma peça de ferro fundido } \\
\text { através de uma ACV de berço-ao-portão que inclui a produção } \\
\text { de gusa em alto-forno. Considera categorias como pegada de } \\
\text { carbono, depleção da camada de ozônio e ecotoxicidade. } \\
\text { Embora não tenha considerado um indicador de energia } \\
\text { acumulada, contempla o consumo de energia de diversas } \\
\text { naturezas e fontes em inventário, além disso inclui cenário de } \\
\text { transporte. }\end{array}$ & $\mathrm{x}$ & $\mathrm{x}$ & $x$ & & $\mathrm{x}$ & 5,0 \\
\hline P16 & $\begin{array}{l}\text { Síntese da dissertação (P26), com foco no cimento. Analisa } \\
\text { diferentes critérios de alocação (mássico, econômico e } \\
\text { expansão das fronteiras) dos impactos da produção de cimento } \\
\text { com três percentuais de substituição de clínquer por escória de } \\
\text { alto-forno. Para tanto, avalia o ciclo de vida da produção de gusa } \\
\text { em dez categorias de impacto com os mesmos critérios de } \\
\text { alocação. }\end{array}$ & $\mathrm{x}$ & $x$ & & $\mathrm{x}$ & & 8,0 \\
\hline P17 & $\begin{array}{l}\text { Simula casos de produção de cobre, LED e gusa de níquel com } \\
\text { diferentes insumos nobres e residuais. No terceiro caso, o autor } \\
\text { avalia o ciclo de vida da produção de gusa de níquel (alternativa } \\
\text { para níquel primário na China) nas categorias de pegada de } \\
\text { carbono, acidificação, eutrofização e formação de ozônio } \\
\text { estratosférico. }\end{array}$ & $\mathrm{x}$ & $x$ & & & $\mathrm{x}$ & 4,0 \\
\hline P18 & $\begin{array}{l}\text { Analisa o potencial de redução de emissão de carbono na } \\
\text { produção de aço pelo uso de biomassa como fonte de carbono } \\
\text { combustível/redutor. Os autores usaram dados secundários da } \\
\text { ACV da produção de carvão vegetal para estimar redução de } \\
\text { impacto na substituição por carvão mineral e coque. }\end{array}$ & & $x$ & & & $\mathrm{x}$ & 1,5 \\
\hline P19 & $\begin{array}{l}\text { Avalia a pegada de carbono da produção de cimento com e sem } \\
\text { substituição parcial de escória de alto-forno tendo em vista } \\
\text { limitações mercadológicas no contexto australiano. Os } \\
\text { resultados demonstram a redução de impacto com essa } \\
\text { iniciativa. }\end{array}$ & & $\mathrm{x}$ & & $\mathrm{x}$ & & 3,0 \\
\hline
\end{tabular}

Rev. Bras. Gest. Amb. Sustent., 2020, vol. 7, n. 16, p. 905-936. 
Tabela 4. Continuação.

\begin{tabular}{|c|c|c|c|c|c|c|c|}
\hline \multirow[b]{2}{*}{$\mathbf{P}$} & \multirow[b]{2}{*}{ Contribuição / conteúdo } & \multicolumn{3}{|c|}{ Pergunta } & \multicolumn{2}{|c|}{ Resposta } & \multirow[b]{2}{*}{ Nota } \\
\hline & & Q1 & Q2 & Q3 & $\begin{array}{l}\text { To- } \\
\text { tal }\end{array}$ & $\begin{array}{l}\text { Par- } \\
\text { cial }\end{array}$ & \\
\hline P20 & $\begin{array}{l}\text { Avalia o ciclo de vida da produção de Magnetita de titânio- } \\
\text { vanádio através da produção integrada de aço. Para tanto, os } \\
\text { autores estimaram os impactos em várias categorias de todas as } \\
\text { macro-etapas do processo, comparando-as, inclusive da } \\
\text { produção de gusa. }\end{array}$ & $\mathrm{x}$ & $\mathrm{x}$ & & $\mathrm{x}$ & & 8,0 \\
\hline P21 & $\begin{array}{l}\text { Avalia as tecnologias de captura e armazenamento de carbono } \\
\text { na siderurgia. Compara métodos de captura pós-combustão e o } \\
\text { alto-forno de oxigênio (modificado) e suas vantagens. }\end{array}$ & & $\mathrm{x}$ & & & $\mathrm{x}$ & 1,5 \\
\hline P22 & $\begin{array}{l}\text { Artigo expandido do artigo de congresso (P28). Avalia o ciclo de } \\
\text { vida da produção de gusa com foco na substituição parcial de } \\
\text { diferentes tipos de biomassa por coque. O estudo de caso foi } \\
\text { feito considerando as implicações de pegada de carbono e de } \\
\text { custo de tais substituições. Demonstraram a redução de } \\
\text { emissão e custo em alguns casos. }\end{array}$ & $x$ & $\mathrm{x}$ & & $\mathrm{x}$ & & 8,0 \\
\hline P23 & $\begin{array}{l}\text { Analisa a substituição de coque por carvão vegetal } \\
\text { convencional, madeira torrificada e gás natural sintético à base } \\
\text { de madeira. Os autores estimam as emissões de carbono } \\
\text { inerentes à produção e uso desses insumos, consumo de energia } \\
\text { no alto-forno para cada cenário e avaliação de custo de } \\
\text { investimento de implantação. }\end{array}$ & & $x$ & $\mathrm{x}$ & $\mathrm{x}$ & & 5,0 \\
\hline P24 & $\begin{array}{l}\text { Avalia o ciclo de vida da produção de gusa com foco na } \\
\text { substituição parcial de coque por uma série de agentes } \\
\text { redutores, como carvão vegetal, antracito, óleo pesado, alcatrão, } \\
\text { gás natural, resíduos de plástico e outros. Estimaram a pegada } \\
\text { de carbono e a depleção de recursos fósseis pela exergia da } \\
\text { produção de gusa nesses cenários. }\end{array}$ & $\mathrm{x}$ & $\mathrm{x}$ & & $\mathrm{x}$ & & 8,0 \\
\hline P25 & $\begin{array}{l}\text { Avalia o ciclo de vida de alto-forno convencional e melhorado, e } \\
\text { forno COREX, nos cenários com e sem tecnologias de captura de } \\
\text { carbono. Além da pegada de carbono, uma gama de outras } \\
\text { categorias dentro do método ReCiPe foram analisadas. Destaca- } \\
\text { se que ao implementar captura e armazenamento de carbono } \\
\text { gerando créditos não significa melhorar todo o perfil ambiental } \\
\text { nos cenários analisados. }\end{array}$ & $\mathrm{x}$ & $\mathrm{x}$ & & $\mathrm{x}$ & & 8,0 \\
\hline P26 & $\begin{array}{l}\text { Analisa diferentes critérios de alocação (mássico, econômico e } \\
\text { expansão das fronteiras) dos impactos da produção de cimento } \\
\text { com três percentuais de substituição de clínquer por escória de } \\
\text { alto-forno. Para tanto, avalia o ciclo de vida da produção de gusa } \\
\text { em dez categorias de impacto com os mesmos critérios de } \\
\text { alocação. }\end{array}$ & $\mathrm{x}$ & $x$ & & $\mathrm{x}$ & & 8,0 \\
\hline P27 & $\begin{array}{l}\text { Avalia o ciclo de vida com ACV de berço-ao-portão do aço por } \\
\text { duas rotas diferentes e cenários com substituição parcial de } \\
\text { coque por antracito e carvão vegetal. As categorias avaliadas } \\
\text { foram pegada de carbono e demanda acumulada de energia. } \\
\text { Resultados foram mostrados apenas para o aço e escória de } \\
\text { alto-forno, não sendo possível extrair informações sobre a } \\
\text { produção de gusa. }\end{array}$ & $\mathrm{x}$ & $x$ & $\mathrm{x}$ & & $\mathrm{x}$ & 5,0 \\
\hline P28 & $\begin{array}{l}\text { Avalia o ciclo de vida da produção de gusa com foco na } \\
\text { substituição parcial de diferentes tipos de biomassa por coque. } \\
0 \text { estudo de caso foi feito considerando as implicações de } \\
\text { pegada de carbono e de custo de tais substituições. } \\
\text { Demonstraram a redução de emissão e custo em alguns casos. }\end{array}$ & $\mathrm{x}$ & $x$ & & $\mathrm{x}$ & & 8,0 \\
\hline
\end{tabular}


Tabela 4. Continuação.

\begin{tabular}{|c|c|c|c|c|c|c|c|}
\hline \multirow[b]{2}{*}{$\mathbf{P}$} & \multirow[b]{2}{*}{ Contribuição / conteúdo } & \multicolumn{3}{|c|}{ Pergunta } & \multicolumn{2}{|c|}{ Resposta } & \multirow[b]{2}{*}{ Nota } \\
\hline & & Q1 & Q2 & Q3 & $\begin{array}{l}\text { To- } \\
\text { tal }\end{array}$ & $\begin{array}{l}\text { Par- } \\
\text { cial }\end{array}$ & \\
\hline P29 & $\begin{array}{l}\text { Avalia o ciclo de vida com ACV de berço-ao-portão do gusa de } \\
\text { alto-forno. As categorias avaliadas foram depleção de recursos e } \\
\text { combustíveis fósseis, e demanda acumulada de energia e } \\
\text { exergia. Seus principais resultados mostram o potencial de } \\
\text { substituição de parte dos insumos fósseis por resíduos } \\
\text { poliméricos. }\end{array}$ & $\mathrm{x}$ & & $\mathrm{x}$ & $\mathrm{x}$ & & 7,0 \\
\hline P30 & $\begin{array}{l}\text { Avalia o ciclo de vida do gusa de alto-forno e via COREX em } \\
\text { diferentes cenários. Uma gama de categoria avaliadas foi } \\
\text { estimada, porém no que se refere a energia, apenas a energia } \\
\text { operacional. Seus principais resultados mostram que reciclar o } \\
\text { gás de topo reduz impacto e que o COREX não apresentou perfil } \\
\text { ecológico superior ao alto-forno. }\end{array}$ & $\mathrm{x}$ & $\mathrm{x}$ & & $\mathrm{x}$ & & 8,0 \\
\hline P31 & $\begin{array}{l}\text { Analisa aspectos econômicos e técnicos de captura e } \\
\text { armazenamento de carbono em uma série de setores } \\
\text { industriais, incluindo o siderúrgico. Outras emissões foram } \\
\text { estudadas, como NOx, SOx e outros. }\end{array}$ & & $\mathrm{x}$ & & & $\mathrm{x}$ & 1,5 \\
\hline P32 & $\begin{array}{l}\text { Analisa emissões de carbono na produção de eletricidade e } \\
\text { eficiência energética na indústria mexicana. Emissões fugitivas } \\
\text { na produção de eletricidade tem participação significativa nas } \\
\text { emissões da siderurgia no país. Foram estimadas as emissões } \\
\text { dos principais subprocessos da produção de aço. }\end{array}$ & & $x$ & $x$ & & $\mathrm{x}$ & 2,5 \\
\hline P33 & $\begin{array}{l}\text { Avalia o ciclo de vida de algumas rotas de obtenção de ferro e } \\
\text { aço através de ACV de berço ao portão e análise econômica dos } \\
\text { cenários. A substituição de coque ou carvão mineral por carvão } \\
\text { vegetal mostrou redução na pegada de carbono, mas não } \\
\text { competitividade em termos de custo naquele cenário. }\end{array}$ & & $\mathrm{x}$ & & $\mathrm{x}$ & & 3,0 \\
\hline P34 & $\begin{array}{l}\text { Analisa o fluxo de material na cadeia produtiva do carvão } \\
\text { vegetal e o ciclo de vida do gusa produzido via carvão vegetal } \\
\text { em alto-forno naquele contexto em duas categorias. Resultados } \\
\text { mostram que o uso de carvão vegetal a partir de madeira de } \\
\text { reflorestamento no lugar de coque pode reduzir a pegada de } \\
\text { carbono. Já para formação de ozônio estratosférico, destacou o } \\
\text { controle e recuperação de gases condensáveis na carbonização } \\
\text { da madeira e o aproveitamento do gás de alto-forno para } \\
\text { geração de eletricidade. }\end{array}$ & $\mathrm{x}$ & $\mathrm{x}$ & & $\mathrm{x}$ & & 8,0 \\
\hline P35 & $\begin{array}{l}\text { Analisa a produção de ferro e aço por simulação e otimização de } \\
\text { processos com foco em eficiência energética e emissão de } \mathrm{CO}_{2} . \\
\text { Os autores mostraram que é possível atingir reduções } \\
\text { significativa de consumo de energia e emissões otimizando os } \\
\text { processos produtivos e incluindo sucata como fonte alternativa } \\
\text { de ferro. }\end{array}$ & & $\mathrm{x}$ & $\mathrm{x}$ & & $\mathrm{x}$ & 2,5 \\
\hline P36 & $\begin{array}{l}\text { Analisa o setor de ferro e aço japonês sob várias perspectivas, } \\
\text { tanto produtivas quanto mercadológicas e de regulação. A } \\
\text { avaliação técnica inclui aspectos como eficiência energética, } \\
\text { substituição do carvão mineral, aumento da reciclagem no } \\
\text { processo, remoção de } \mathrm{CO}_{2} \text { e disposição no mar, otimização de } \\
\text { consumo de materiais e outros. }\end{array}$ & & $\mathrm{x}$ & $x$ & & $\mathrm{x}$ & 2,5 \\
\hline
\end{tabular}


Estas 36 publicações possuem respostas às perguntas levantadas em alguma medida, sendo 15 do estado da arte e 21 do período anterior. Houve mais respostas parciais $(61 \%)$ do que totais (39\%). Somente 15 trabalhos $(42 \%)$ responderam à pergunta central da pesquisa (Q1), sendo 11 de forma mais próxima da integralidade.

A Figura 3 até a Figura 7 exibem o perfil do problema de pesquisa da amostra final de publicações por categoria analisada. Cada análise buscou responder a um questionamento:

- O tema está em evidência nos dias em curso?

Um dos aspectos que pode ser associado à resposta dessa questão é a quantidade de publicações por ano e uma possível tendência de crescimento (Figura 3).

- O tema tem relevância científica?

Essa pode ser tanto maior quanto maior for a quantidade de publicações conceituadas e respaldadas, como artigos de periódicos que normalmente passam por avaliação pelo menos duplo-cega, mas também livros, capítulos, teses, dissertações e relatórios técnicos como anuários (Figura 4).

- Quais são os grupos de pesquisa que mais contribuíram?

Um levantamento de todos os autores e coautores das publicações resultantes indica os principais estudiosos de tópicos associados ao tema (Figura 5).

- Onde estão os principais interessados?

Uma das formas de inferir sobre essa questão é enumerar o país de filiação do primeiro autor dos trabalhos da amostra (Figura 6).

- 0 tema é inédito?

Pode-se classificar as publicações resultantes por grau de aderência, de acordo com nota ou pontuação atribuída dentro dos critérios definidos (Figura 7).

Verificou-se uma tendência de crescimento da quantidade de estudos a partir de 2011, com destaque para o período de ascensão de 2012 - 2015, mantendo-se nos 3 anos subsequentes (Figura 3). Isso demonstra o aumento da importância da temática, tratando a questão na perspectiva de ACV.

Observou-se uma tendência em encontrar documentos mais longos (teses, dissertações e relatórios) no período anterior ao estado da arte, e mais artigos de periódicos em pesquisas recentes, tratando as questões de forma mais pontual.

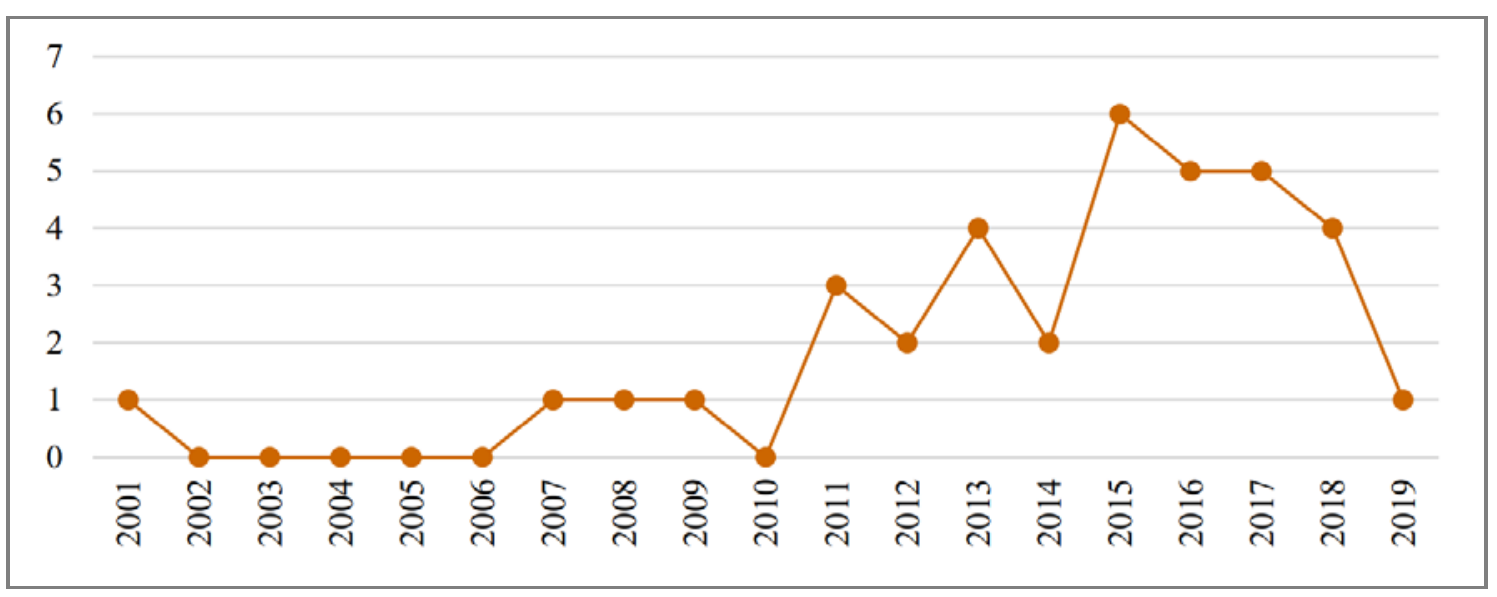

Figura 3. Quantidade de publicações por ano. 
Cerca de 58\% da amostra é composta por artigos de periódicos, demonstrando a relevância do tema como objeto de discussão em revistas de alto fator de impacto e visibilidade (Figura 4). Do restante, $25 \%$ são teses ou dissertações e os outros $17 \%$ são artigos de congresso, capítulos de livro ou relatórios técnicos.

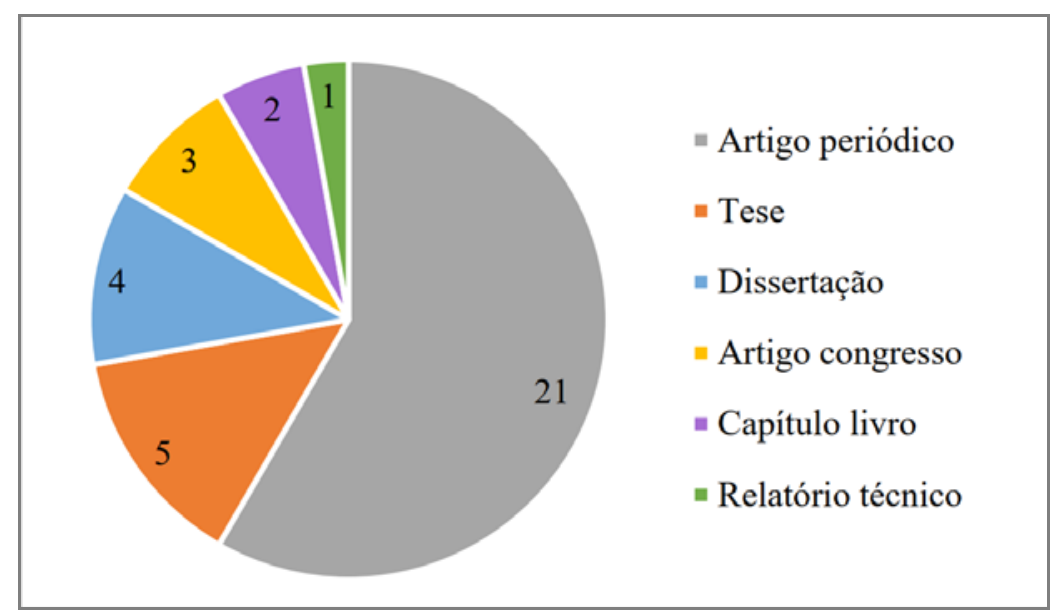

Figura 4. Quantidade de publicações por tipo.

Em grande parte dos achados (76\%), um autor ou coautor teve apenas uma contribuição concernente ao tema. Porém, 13 dos 101 autores publicaram duas vezes ou mais, representando e participando de cerca de 24\% das publicações (Figura 5). Suopajärvi e Fabritius $(2014,2017,2018)$ destacaram-se com mais estudos, sendo coautores das três publicações.

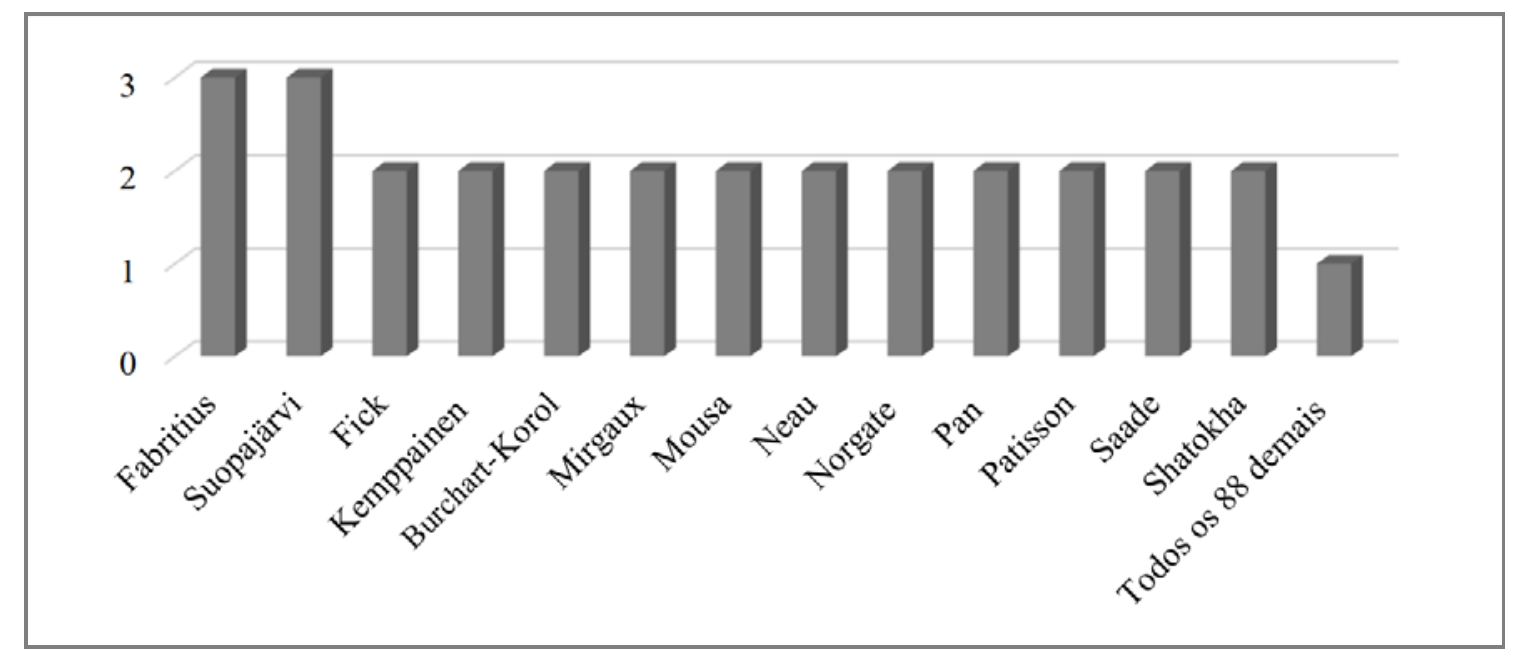

Figura 5. Quantidade de publicações por autoria/coautoria. 
A produção científica por país pode indicar onde há maior discussão sobre o tema. Os países de filiação do primeiro autor com maior produção são a China com 17\%, seguido da Finlândia com 14\%, e Brasil, Austrália e Inglaterra empatados com 8\% (Figura 6). Os $44 \%$ restantes estão divididos entre outros países americanos e europeus.

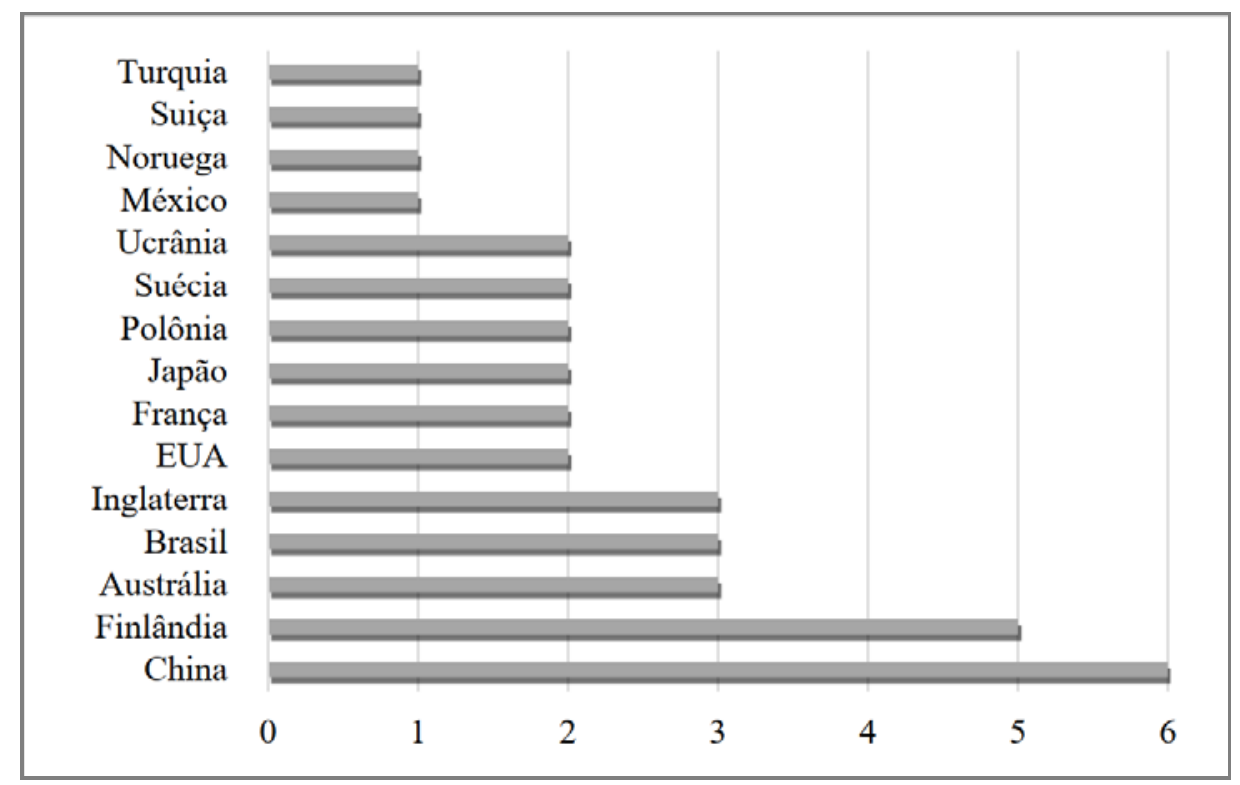

Figura 6. Quantidade de publicações por país de filiação do primeiro autor

Nenhuma das publicações atingiu nota máxima. No entanto, uma parte (28\%) alcançou nota 8,0 demonstrando não apenas que o tema é relevante e tem sido discutido, mas também que os critérios das primeiras etapas de seleção foram assertivos e que as questões de pesquisa estão, de fato, relacionadas (Figura 7).

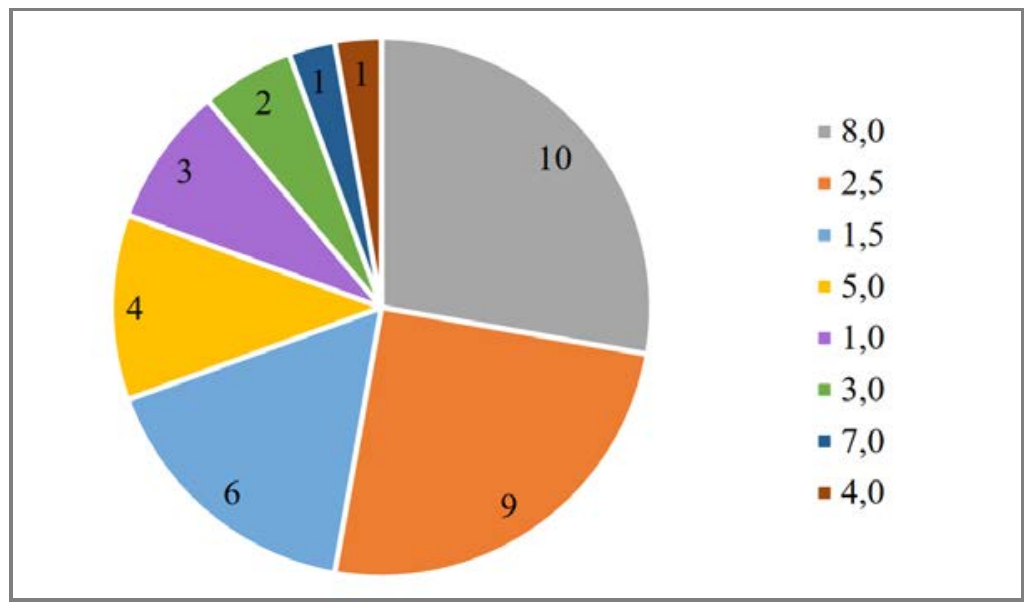

Figura 7. Quantidade de publicações por grau de aderência (nota). 
Os achados com nota final entre 5,0 e 7,0 representam 14\%. Juntos com os de nota 8,0 somam 15 estudos ( $42 \%$ da amostra). Esses representam o conjunto de trabalhos de maior aderência, cujos resultados e constatações tiveram maior influência na análise que segue. Os outros $58 \%$ alcançaram notas entre 1,5 e 4,0 .

Parte considerável dos trabalhos foi de pesquisa original (83\%), isto é, investigações experimentais ou teóricas que produziram evidências sobre redução de emissões, ou de captura e armazenamento de carbono ou, aumento da eficiência energética no contexto da indústria siderúrgica mundial ou local - referentes ao país dos autores.

Porém, alguns trabalhos se propuseram a confrontar estudos originais realizados (17\%), que são revisões de tecnologias disponíveis e ou do estado da arte, envolvendo também questões políticas e regulatórias.

As abordagens mais comuns se pautaram na análise de matérias-primas mais renováveis ou alternativas tecnológicas pontuais e incrementais para melhoria da eficiência energética operacional e/ou redução de emissões da principal rota, o alto-forno, quase sempre associada ao ciclo de vida do aço.

Das tecnologias alternativas, apenas o $\operatorname{COREX}^{\circledR}$ foi objeto de comparação com o alto-forno, não havendo sido encontradas análises dessa natureza sobre outras rotas emergentes de produção de ferro gusa. São tecnologias emergentes Finex ${ }^{\circledR}$, Midrex ${ }^{\circledR}$, HIsmelt ${ }^{\circledR}$, ITmk $^{\circledR}$, Tecnored ${ }^{\circledR}$ e outros (Gordon et al., 2015).

No que concerne ao estudo de matérias-primas do processo, apenas um trabalho, a publicação P35 (Ryman, 2007), considerou alternativas de fonte de ferro, como resíduos, sucata, carepa e outros. A maioria predominante teve foco nas fontes de carbono, agente redutor e ao mesmo tempo combustível.

Em alguns casos, citou-se o esgotamento de recursos a partir de estimativas de escassez de fontes de combustíveis fósseis, por exemplo. Não foram encontrados resultados e discussões sobre danos ao ecossistema ou saúde humana.

A produção de ferro e aço tem maior emissão de $\mathrm{CO}_{2}$ do que qualquer outro setor industrial (Hasanbeigi et al., 2013). Desse modo, a pegada de carbono é a categoria de avaliação de impacto de maior importância para indústria siderúrgica nos dias em curso, haja vista seus efeitos na mudança climática e as políticas de creditação/precificação de carbono no cenário mundial.

Todavia, essa categoria não é capaz de representar sozinha o perfil ambiental de um produto ou serviço industrial. Existem outras formas substanciais de causar impactos, assim como danos ao ecossistema, aos recursos naturais e à saúde humana.

Além disso, menções ou atendimento às diretrizes da Regra de Categoria de Produto (RCP) para análises do setor de ferro e aço (IEPDS, 2015) não foram encontradas. Esse documento é produzido por um comitê especializado estabelecendo critérios e diretrizes aceitas internacionalmente como referência para o desenvolvimento de declarações ambientais em cada setor.

Dos trabalhos que conduziram uma ACV, apenas cinco estudos avaliaram quatro ou mais categorias de impacto, a fim de gerar um perfil ambiental robusto para obter constatações mais e consistentes e abrangentes: P14 (Olmez et al., 2016), P20 (Chen et al., 2015), P25 (Choi, 2013), P26 (Saade, 2013), P30 (Ding; Li, 2011).

A RCP recomenda a inclusão de cinco categorias de emissão IEPDS (2015), que associadas às categorias de depleção de reservas minerais e fósseis - relevantes para análise desses processos intensivos em consumo de recursos -, e à contabilização da energia pré-operacional, somam pelo menos oito categorias.

Apesar de a eficiência energética ser uma grandeza técnica, sua existência indispensável como indicador de desempenho em processos produtivos possui implicações ambientais indiretas e indissociáveis, e por isso passou a ser considerada como uma categoria impacto. 
Nesta perspectiva, uma análise ampla da pegada energética não reflete apenas aspectos da etapa de operação ou uso, mas também impactos cumulativos das etapas préoperacionais, detalhando demanda energética do processo em relação aos fornecedores, por exemplo, ou conteúdo renovável versus não renovável das fontes de energia do sistema.

\section{Redes bibliométricas}

Com o intuito de revelar os tópicos em maior evidência nas publicações acadêmicas dentro desse tema, foram feitos mapeamentos da literatura na forma de redes bibliométricas.

Essas redes ou mapas são baseadas na quantidade de ocorrências dos termos seja de uma palavra, sigla, autor, citação, periódico, etc. - em um conjunto de publicações, na interligação entre esses termos e na intensidade das ligações.

Isso possibilita obter uma visão geral de um certo campo de pesquisa, bem como descobrir a interconexão entre diferentes tópicos, novos descritores não pensados como relevantes anteriormente, e revelar sequência cronológica dos subtemas pesquisados ao longo dos anos. Outras vantagens são que além de não ser necessário fazer uma leitura dos trabalhos, os mapas gerados incluem os documentos indisponíveis para acesso ou download.

Neste trabalho, tais redes foram geradas no VOSviewer ${ }^{\circledR}$, um software que produz mapas contendo, neste caso em específico, os termos encontrados em título, resumo e palavras-chave das publicações recuperadas nas buscas.

O mapa é formado por clusters, que são agrupamentos de termos com maior inter-relação, sendo cada agrupamento representado por uma cor. Cada termo só pode pertencer a um único cluster, sendo que sua quantidade de ocorrências é representada pelo tamanho relativo da indicação gráfica e sua "co-ocorrência" com outros termos é representada pelas linhas que os ligam.

Alternativamente ao formato de clusters, um mesmo mapa pode ser representado com um gradiente de cores que associa os termos em destaque e o respectivo período das publicações que os contém.

Neste trabalho, realizou-se uma pesquisa bibliométrica em 20 de maio de 2019 nos repositórios Web of Science e Scopus sem restrição de período (ano de publicação). Esses repositórios foram utilizados por serem compatíveis com o software.

0 termo "alto-forno" foi incluído nesta segunda análise, por ser a rota principal de obtenção de ferro gusa e contribuir para a captação de mais trabalhos, bem como pelo fato de a revisão sistemática ter mostrado uma escassez substancial na quantidade de trabalhos acerca de outras rotas.

Utilizou-se a seguinte estrutura de string: o primeiro termo foi composto pelos descritores referentes ao objeto de estudo (("pig iron") OR (ironmaking) OR (hotmetal) OR ("blast furnace")); e o segundo, separado do primeiro pelo operador AND, composto pelo método científico de análise de impacto ((lca) OR ("life cycle assessment")).

Em seguida, os datasets foram baixados e importados para o programa para então gerar as redes bibliométricas. Uma pesquisa com descritores em português também foi realizada, porém nenhum registro foi encontrado.

Análise e síntese. As buscas foram realizadas no dia 9 de abril de 2019. Foram recuperados 195 documentos no Scopus e 175 no Web of Science. As redes geradas são mostradas nas figuras a seguir. As Figura 8 e Figura 9 são referentes ao Scopus, já as Figura 10 e Figura 11 ao Web of Science. 


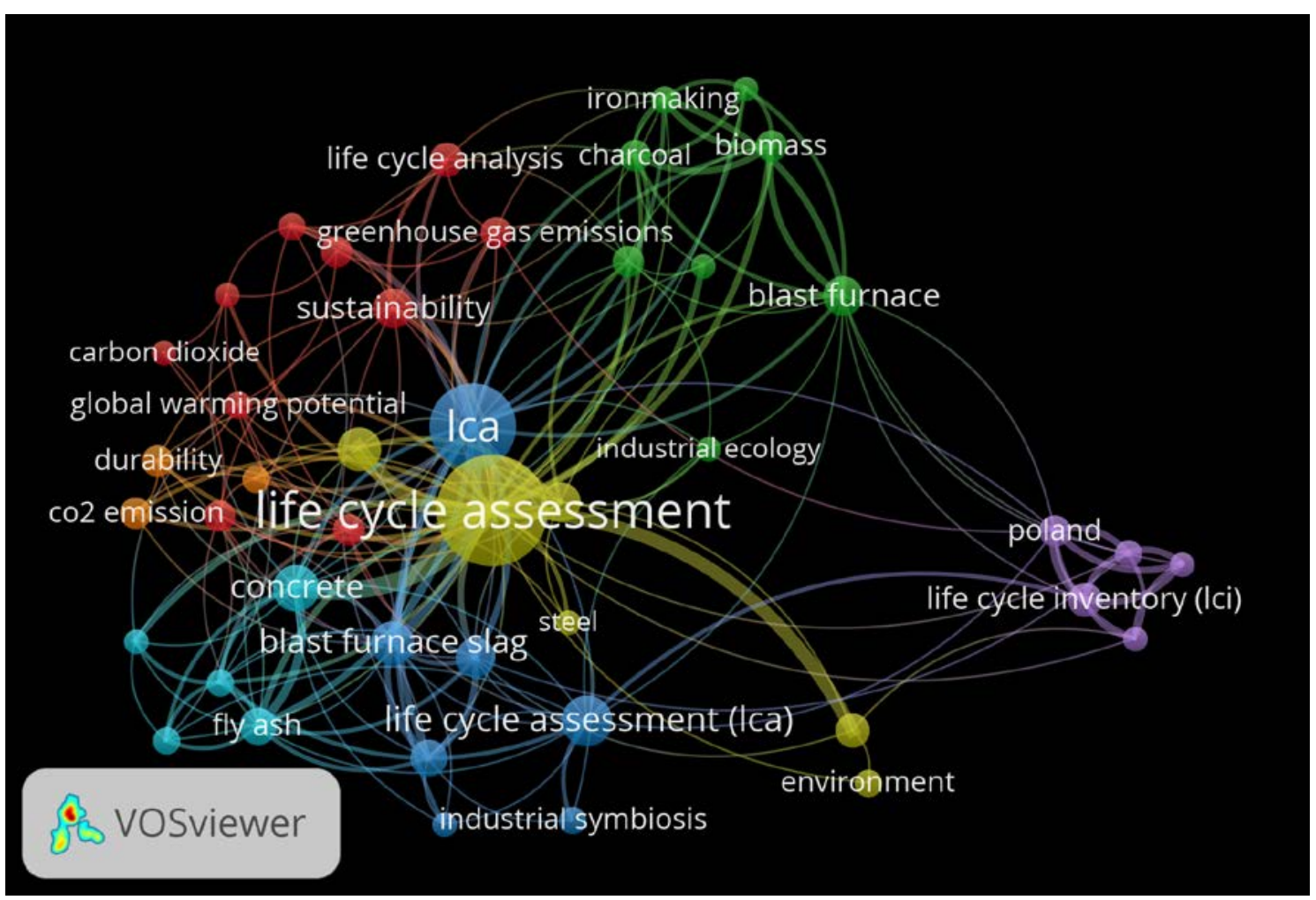

Figura 8. Rede bibliométrica gerada na busca no Scopus em formato de cluster.

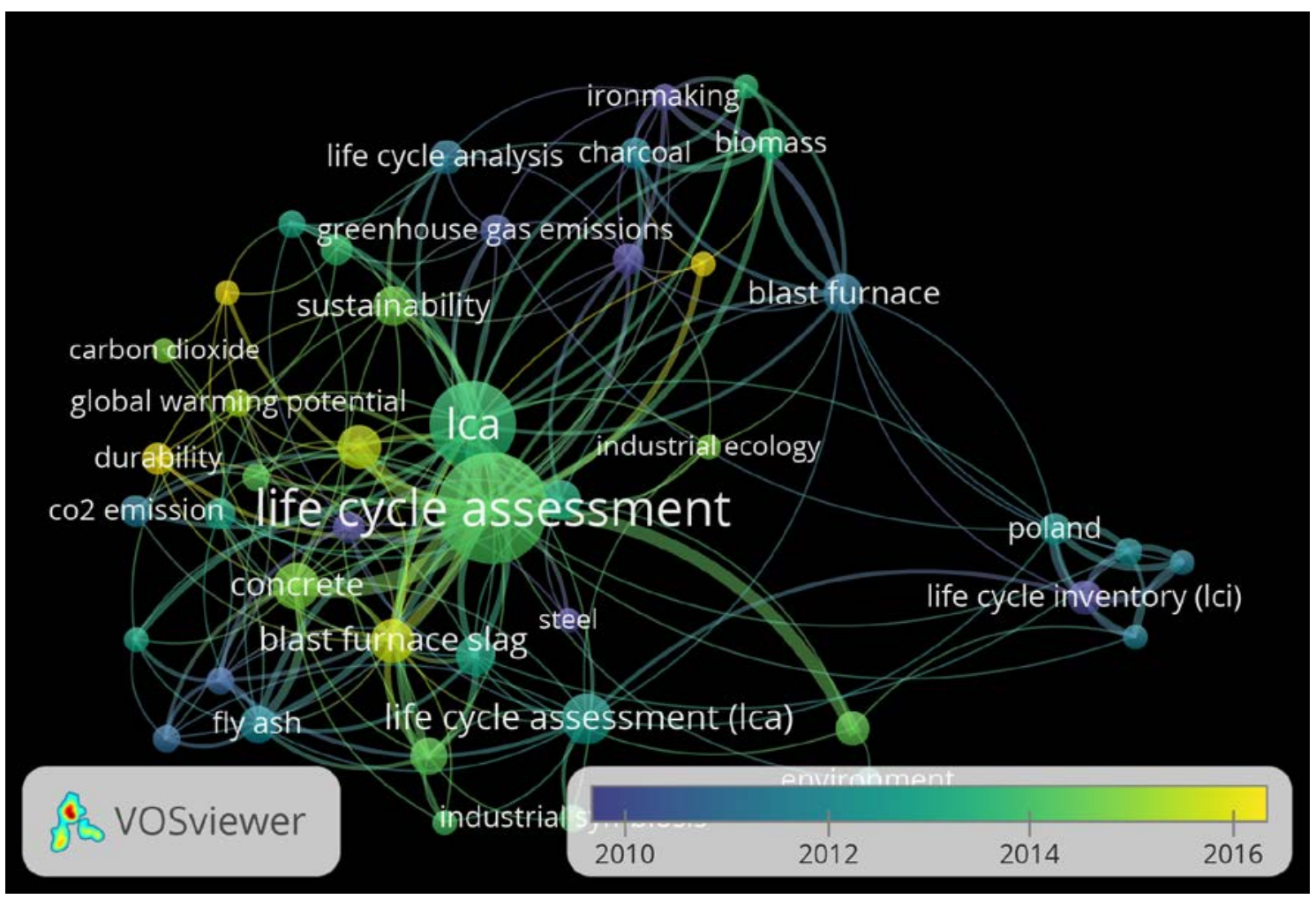

Figura 9. Rede bibliométrica gerada em busca no Scopus em formato cronológico. 


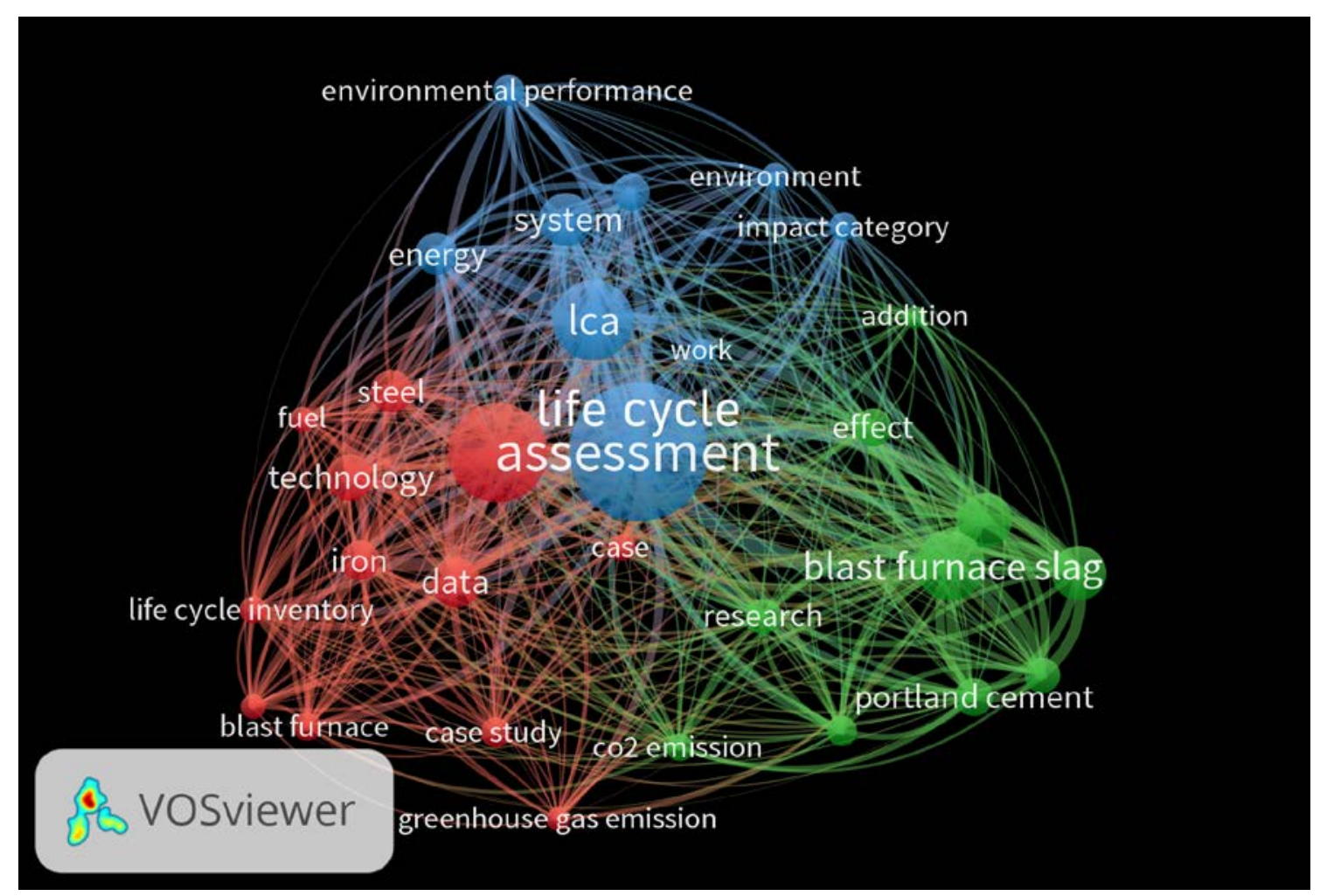

Figura 10. Rede bibliométrica gerada em busca no Web of Science em formato de cluster.

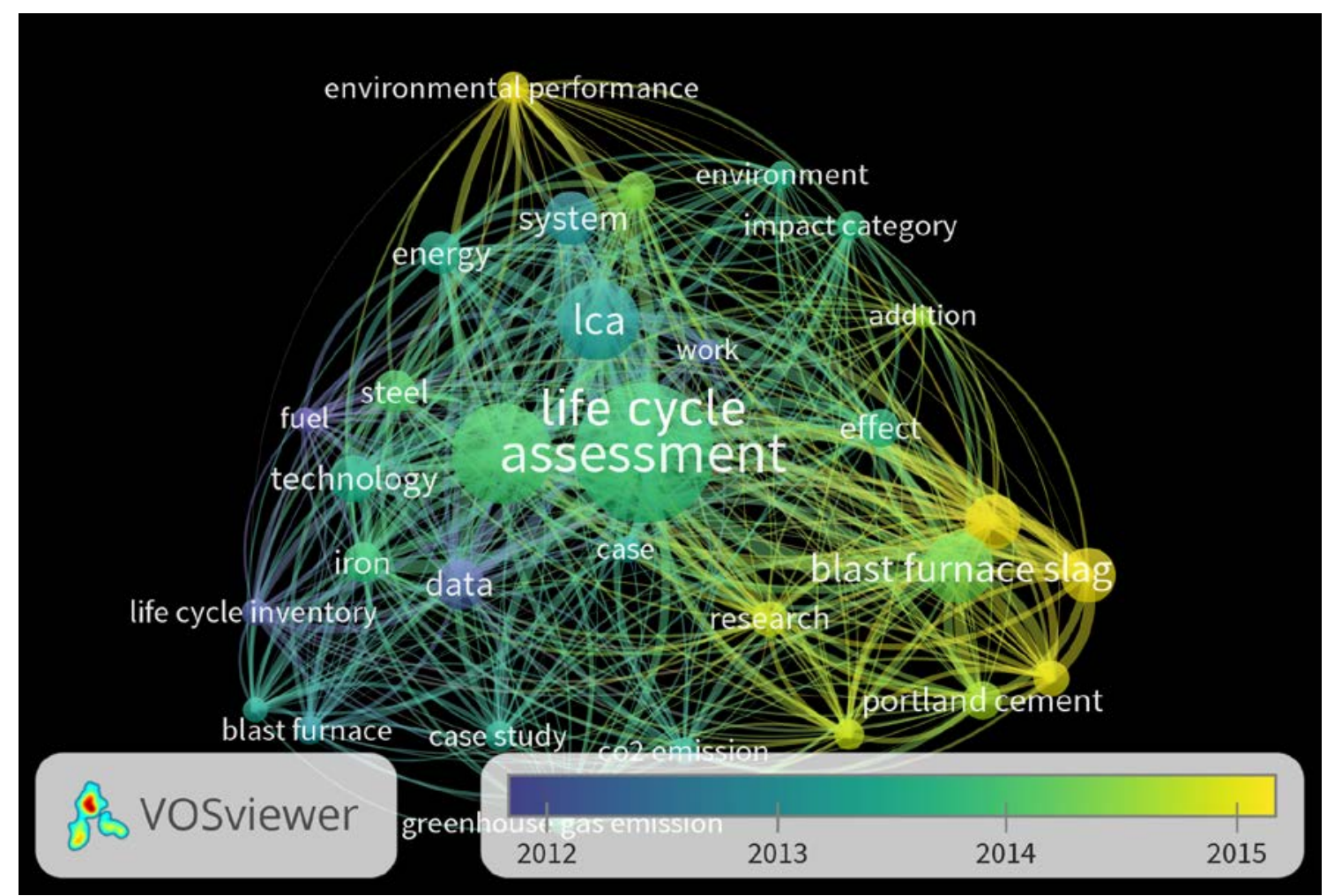

Figura 11. Rede bibliométrica gerada em busca no Web of Science em formato cronológico. 
0 primeiro mapa da pesquisa de cada repositório apresenta coloração no formato de clusters, e a segunda, de associação cronológica. Na otimização padrão do algoritmo do software, as redes geradas da amostra do Scopus apresentaram maior quantidade de clusters, bem como maior período de abrangência dos termos e suas respectivas publicações do que no Web of Science.

Em uma análise conjunta dessas redes, observa-se um desenvolvimento considerável nesse campo de estudo nos últimos anos, visto que a maior parte das publicações é de 2010 - 2019. Esse período contém 87\% dos trabalhos recuperados no Scopus e $89 \%$ dos encontrados no Web of Science.

De modo geral, é possível perceber que o termo associado à ferramenta de análise, a ACV, está destacado em uma posição central e com a maior quantidade de ocorrências em relação aos demais, interrelacionando-se de forma intensa com os principais descritores de cada cluster.

Ao observar os clusters formados, é possível fazer tentativas de inferência sobre as causas e consequências da interconexão entre os descritores. Por exemplo, nota-se uma intensa ligação entre a expressão escória de alto-forno e os termos cimento, concreto e pozolana.

Isso pode indicar que alguns estudos se voltaram à questão dos resíduos gerados e seu potencial reuso, que ao servirem como insumo para outros sistemas de produto, passam a ter valor agregado e deixam de ser caracterizados como subprodutos do processo, tornando-se coprodutos.

Outra inter-relação que se sobressai é a de combustíveis, como carvão vegetal originado de biomassa, e as emissões de GEE e $\mathrm{CO}_{2}$. Esses elementos estão intimamente relacionados haja vista o fluxo de carbono na cadeia de processos do ciclo de vida de produção de ferro gusa.

Outra forte ligação pode ser identificada entre os termos de desempenho ambiental e de sistema, energia e categorias de impacto, apontando para uma visão mais sistêmica que inclui a perspectiva de energia, como categoria de impacto técnica, acoplando às convencionais categorias ambientais.

Uma ideia da evolução cronológica da discussão científica desse tema também pode ser extraída desses mapas, como mostrado na Tabela 5. Vale ressaltar que essa análise não é uma representação profunda dos achados na pesquisa feita para produção das redes, e não demonstra a síntese de um apanhado exaustivo de evidências.

Tabela 5. Tópicos de maior destaque por ano nos repositórios consultados.

\begin{tabular}{|c|l|l|}
\hline Repositório & Ano & Descritores referentes aos tópicos de maior destaque \\
\hline S & 2010 & Inventário de ciclo de vida; Produção de ferro; Produção de aço; GEE \\
\hline W & \multirow{2}{*}{2012} & Dados; Inventário de ciclo de vida; Combustível \\
\cline { 3 - 3 } S & 2013 & Alto-forno; ACV; Emissão $\mathrm{CO}_{2}$; Carvão Vegetal \\
\hline W & \multirow{2}{*}{2014} & $\begin{array}{l}\text { ACV; Sustentabilidade; Ecologia industrial; Simbiose Industrial; Biomassa; } \\
\text { Concreto; Aquecimento Global }\end{array}$ \\
\cline { 3 - 3 } S & 2015 & $\begin{array}{l}\text { Categoria de impacto; Ferro e aço; GEE } \\
\text { Pesquisa }\end{array}$ \\
\hline W & 2016 & Escória de Alto-forno; Durabilidade \\
\hline W & &
\end{tabular}

Acrônimos: S - Scopus; W - Web of Science. 
Todavia, mesmo não havendo possibilidade de extrair conclusões incontestáveis desses resultados, é possível inferir sobre as questões centrais em pauta, como ocorreu a transição entre os tópicos no período observado, bem como as principais dificuldades enfrentadas a respeito.

Nota-se que as contribuições iniciais identificadas nas redes tratavam dos dados da produção de ferro e aço, possivelmente da construção de inventários de emissão de GEE ou, até mesmo, da dificuldade de obtenção desses dados visto que é um limitante usual na realização de ACVs.

Em seguida, os termos em maior evidência fazem referência aos combustíveis utilizados no processo, a exemplo da substituição de fontes fósseis por carvão vegetal, e uma potencial redução nas emissões associadas de $\mathrm{CO}_{2}$.

Então, o alto-forno passa para o papel central, sendo encontrado associado a termos que fazem menção às tecnologias empregadas e a uma perspectiva de sistemas, bem como a estudos de caso possivelmente conduzidos para produzir evidências primárias do balanço ecológico dessa rota.

Os conceitos de sustentabilidade, ecologia e simbiose industrial vem à tona, parecendo acrescentar uma visão um pouco mais teorética e profunda da questão ambiental, bem como evidenciar as discussões externas à indústria, desdobrada em uma certa pressão por ações mitigadoras e ecologicamente responsáveis do setor siderúrgico.

Em seguida, passam a ser discutidas as categorias de impacto, com a categoria de aquecimento global em evidência, referente às emissões de GEE resultantes do processo. Ao final do período destacado, observa-se o enfoque no desempenho ambiental, onde se enfatiza a questão dos resíduos sólidos derivados do processo, sendo a escória o principal deles, e seu potencial de reuso como matéria-prima para produção de cimentos.

Neste ponto, discutem-se os potenciais efeitos gerados nas propriedades físicas, como a durabilidade, dos elementos de construção produzidos a partir desse cimento com substituição parcial do clínquer pela escória.

\section{Pesquisa de patentes}

Com o propósito de entender e visualizar a mobilização da indústria a respeito da produção tecnológica e inovativa dentro dessa temática, foi feita uma pesquisa de patentes na plataforma de busca Derwent Innovation ${ }^{\circledR}$ através de acesso concedido ao SENAI CIMATEC.

A plataforma Derwent é gerenciada pela Clarivate Analytics que gerencia serviços de repositórios científicos e de patentes, e detém também o Web of Science Group. Considerou-se o período de 1999 -2019, visto que patentes com reivindicações de inovação ainda em vigor nos dias em curso foram registradas dentro dos últimos 20 anos.

Foram utilizados descritores apenas em inglês, visto que patentes escritas em qualquer língua tem necessariamente uma versão em inglês, sobretudo de título, resumo e reivindicações. 0 primeiro termo da string contemplou o produto ((c"pig iron") OR (hotmetal)) NOT (("raw iron") OR (steel))).

Neste caso em específico, verificou-se a necessidade de impor a não inclusão de achados com os termos "ferro cru", pois se refere ao estado mais primitivo do material anterior à redução, e "aço", pois havia muitas patentes com esse termo que incluíam também em algum ponto do texto descritores como "ferro gusa", embora não fosse uma patente específica do processo produtivo desse último.

O Segundo elemento, associado com o operador AND, incluiu ( $(*$ furnace OR ironmaking) AND (process $\left.{ }^{*}\right)$ ), descritores referentes ao processo produtivo e não apenas de produto, por se tratar de uma pesquisa de patentes. 0 terceiro termo foi utilizado para refletir a questão ambiental e energética, a saber ((green) OR ("energy efficien*") OR (emission) OR ((ghg) OR ("green house gas*”)) OR (impact*) OR (“low carbon")). 
Análise e síntese. A pesquisa foi realizada em 26 de abril de 2019. Foram encontrados 109 registros de patente concedidas. Os termos mais citados em título, resumo e reivindicações, originalmente em inglês, mas traduzidos para português, estão sumarizados na Tabela 6.

Tabela 6. Descritores identificados com maior ocorrência

\begin{tabular}{|c|l|l|l|}
\hline Ranking & Título & Resumo & Reivindicações \\
\hline 1 & Alto-forno & Minério de ferro & Alto-forno \\
\hline 2 & Minério de ferro & Alto-forno & Ferro gusa \\
\hline 3 & Briquete de minério & Plástico misturado & Sistema \\
\hline 4 & Partículas de plástico & Carvão em pó & Processo \\
\hline 5 & Ferro gusa & Partículas de plástico & Parâmetro \\
\hline 6 & Carvão em pó & Ferro gusa & Controle \\
\hline 7 & Titânio & Metal quente & Módulo \\
\hline 8 & Gás de topo & Chorume aquoso & Manganês \\
\hline 9 & Carbono & Escória de titânio & Restrição \\
\hline 10 & Escória & Teor de enxofre & Caracterizado \\
\hline
\end{tabular}

Nota-se que os termos alto-forno, minério de ferro e ferro gusa estão entre os mais citados nas três seções, confirmando que são os elementos centrais das inovações. Outras rotas não foram citadas, isto é, o foco do desenvolvimento estava em aprimorar a rota convencional.

Encontra-se em título e resumo mais descritores referentes aos fluxos de entrada e saída do processo siderúrgico - como insumos e resíduos - e suas características, enquanto observa-se na seção de reivindicações uma predominância de referências à processos, parâmetros e controle.

Dentre as reivindicações de inovação das patentes da amostra, o briquete de minério está associado com a forma de inserção de ferro no reator, na forma de compactados finos com ligantes e fluxantes.

0 plástico refere-se a uma alternativa de combustível para o processo, sendo as dimensões de suas partículas importantes para a eficiência da mistura desse plástico que contém rejeitos com um chorume aquoso.

0 titânio remete ao potencial aumento da vida útil do refratário do forno pela adição de dióxido de titânio ao metal quente líquido no interior do reator, melhorando sua interface com a superfície do refratário.

O refratário é um elemento crítico do processo e ao mesmo tempo frágil por se desgastar e necessitar de substituição afetando diretamente o aspecto econômico do projeto. Nota-se a menção de alguns de resíduos, como escória, gás de topo, escória de titânio.

A escória de alto-forno refere-se a duas alternativas de aproveitamento, a primeira para produção de painéis extrudados com cimento e outra um método de moagem para produção de concreto de alto rendimento. A escória de titânio é mencionada em uma tecnologia para redução de ilmenita, um minério com óxido de titânio e ferro.

0 gás de topo remete ao aproveitamento do nitrogênio separado da corrente para produzir produtos químicos a partir de síntese em paralelo ao processo de redução de ferro. 0 descritor relativo ao teor de enxofre faz referência a um método de previsão do teor de enxofre no ferro gusa, um dos indicadores que refletem seu grau de pureza. 


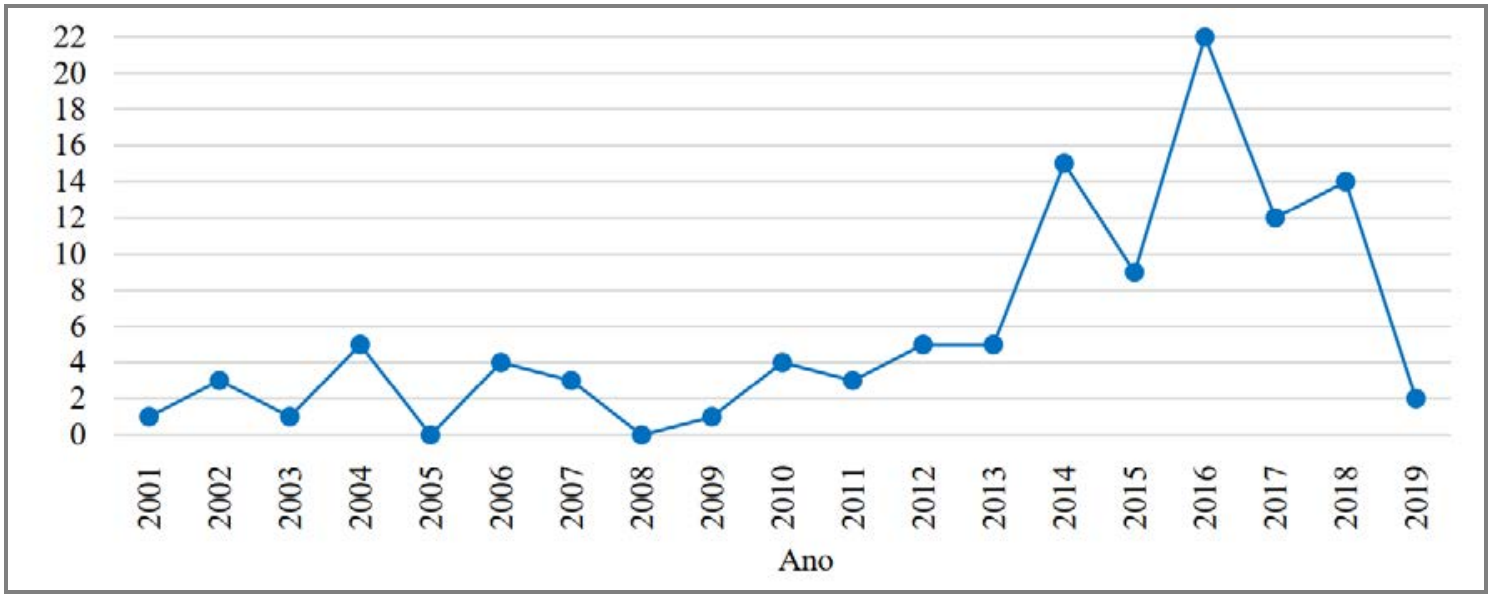

Figura 12. Quantidade de patentes identificadas por ano.

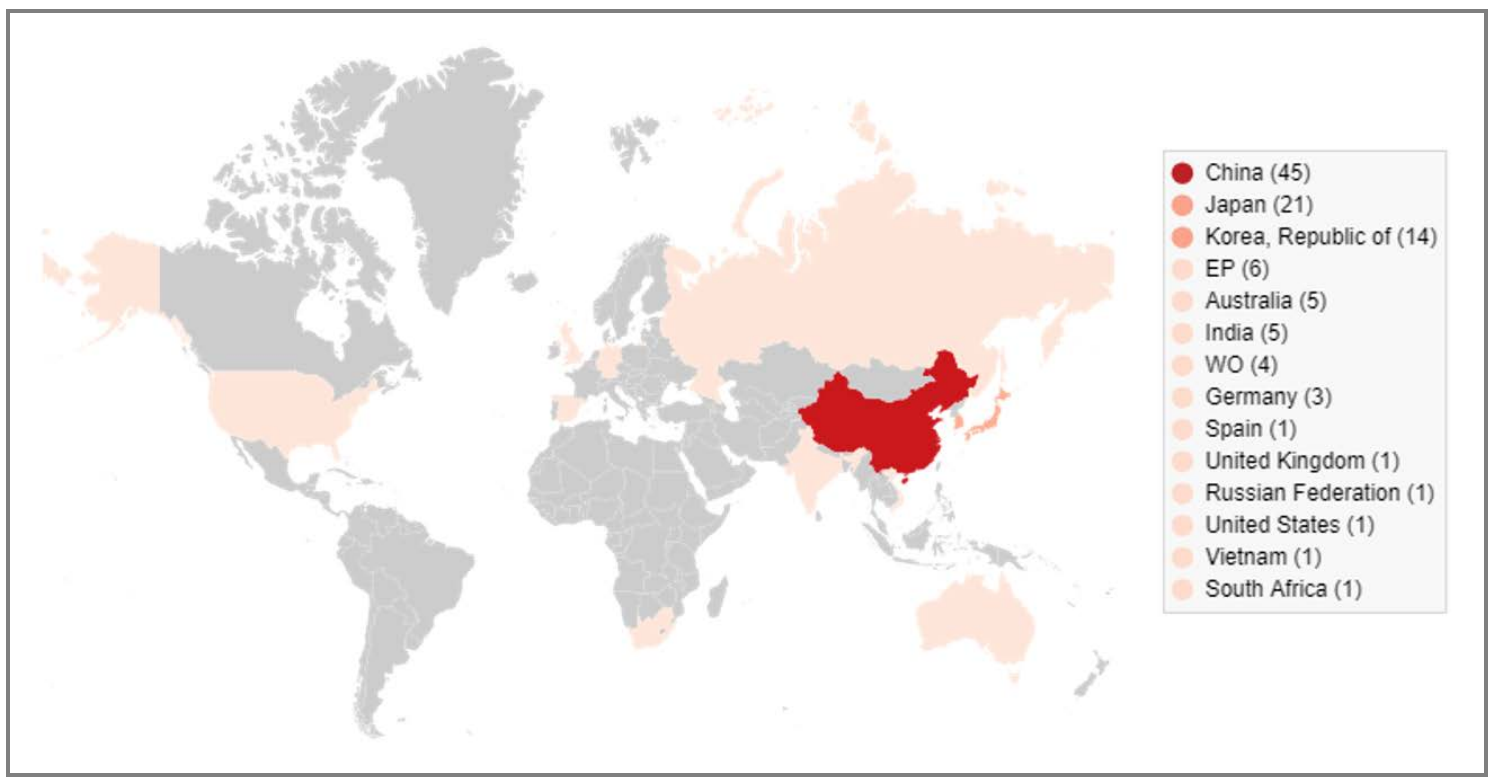

Figura 13. Principais países com patentes concedidas por ano (Derwent Innovation ${ }^{\circledR}$ ).

De modo geral, verificou-se uma tendência de crescimento da quantidade de patentes concedidas, com um aumento acentuado a partir de 2013, mantendo-se nos cinco anos subsequentes (Figura 12). 0 país com mais patentes em quantidade foi a China, mais que o dobro do segundo colocado, o Japão, e mais do que o triplo do terceiro, a Coreia do Sul (Figura 13).

Logo após os três primeiros colocados apareceu o Instituto Europeu de Patentes, seguido de Austrália e Índia. Os outros registros foram encontrados em países da Europa, além de Rússia, EUA, Vietnã e África do Sul. Nota-se que a região oriental do globo tem desenvolvido a maior parte da tecnologia e inovação nesse setor. 


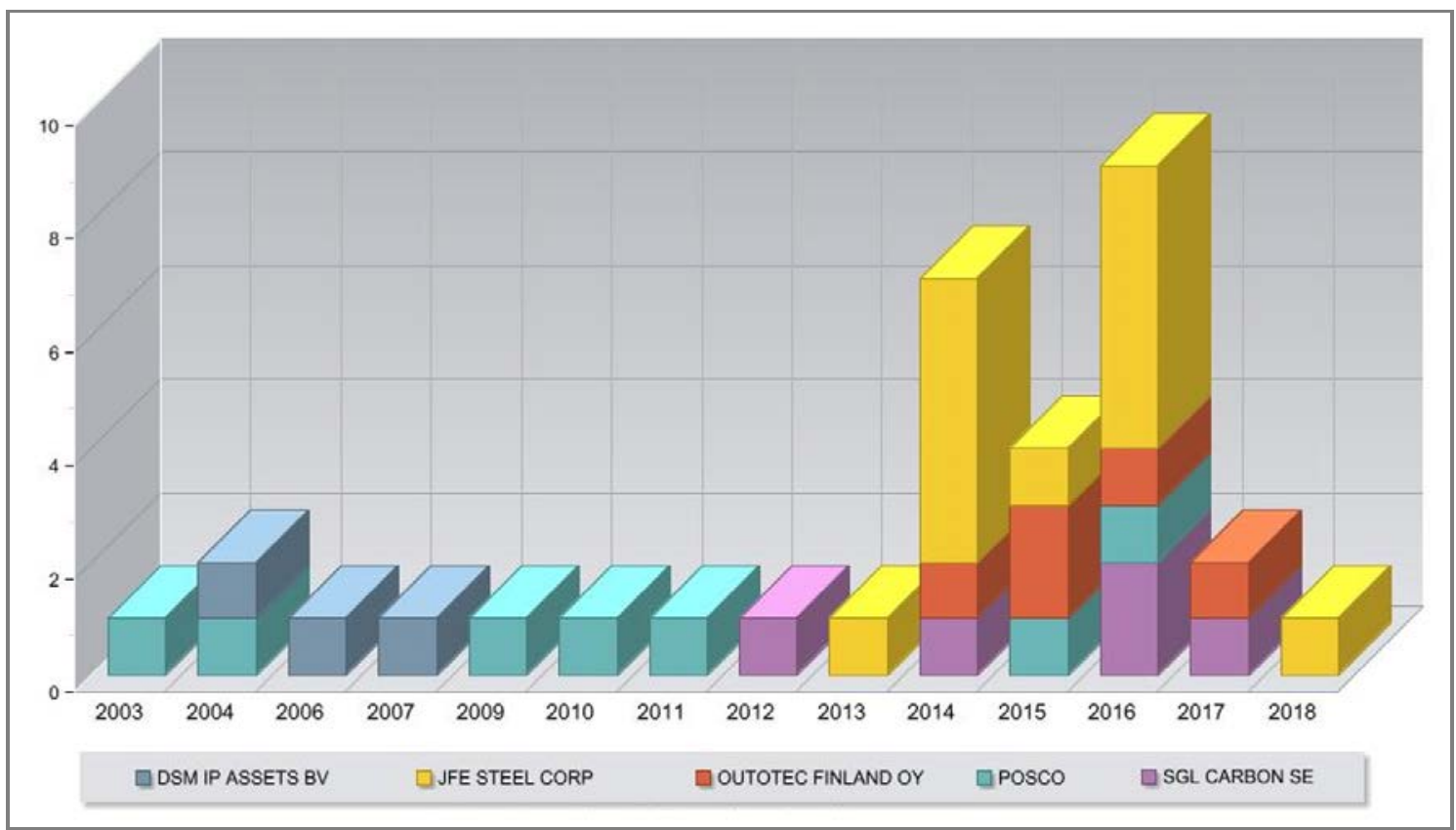

Figura 14. Principais empresas com registros de patente por ano (Derwent Innovation ${ }^{\circledR}$ ).

A Figura 14 apresenta as principais empresas detentoras patentes concedidas por ano. Essas companhias estão em sua maioria sediadas na Europa ou na Ásia. A empresa DSM IP Assets B.V., uma multinacional presente em catorze países com áreas de atuação em saúde, nutrição e materiais, possui três patentes concedidas entre 2004 - 2007.

De forma mais representativa, a Posco, uma siderúrgica de ferro e aço da Coreia do Sul, registrou sete patentes no período de 2003 - 2016. Em período mais recente, de 2012 - 2018, tanto a SGL Carbon SE, companhia sediada na Alemanha com atuação em materiais carbonosos como grafite, fibras e compósitos, quanto a Outotec Finland OU, empresa de tecnologia em siderurgia e mineração finlandesa, registraram cada uma cinco patentes com esse viés.

Nos últimos anos, 2013-2018, a JFE Steel Corporation, uma siderúrgica de aço japonesa, foi a detentora da maior quantidade de patentes concedidas, com treze registros.

\section{Visão geral dos achados}

Uma tendência de crescimento pode ser verificada nos últimos anos tanto em quantidade de registros de patente, que representa a materialização de inovação viabilizada pela indústria siderúrgica, quanto em contribuições da produção científica nesse tema.

Esse processo ocorreu principalmente no período de 2010 - 2019, com destaque para um crescimento acentuado a partir de 2013 - 2014 em ambos os âmbitos, sobretudo em patentes (Figura 15).

Os tópicos da discussão científica, retirados dos mapas bibliométricos, em uma sequência cronológica tratam de questões associadas aos inventários no início do período destacado, passando por estudos de caso, aspectos e impactos do processo, relação de tecnologia e sustentabilidade, até desempenho ambiental. Os países de filiação dos autores são, em ordem decrescente, China, em seguida as Américas, depois Europa, Austrália, Japão e outros. 
No âmbito das inovações, enfoque foi dado para tratamento e reaproveitamento de resíduos, uso de materiais alternativos ou aprimorados como insumos e como adições para resolver problemas específicos das reações de redução, bem como otimização e controle de processo. Os países asiáticos despontam como maiores detentores de patentes, mas também os europeus, regiões onde grande parte das empresas identificadas estão sediadas.

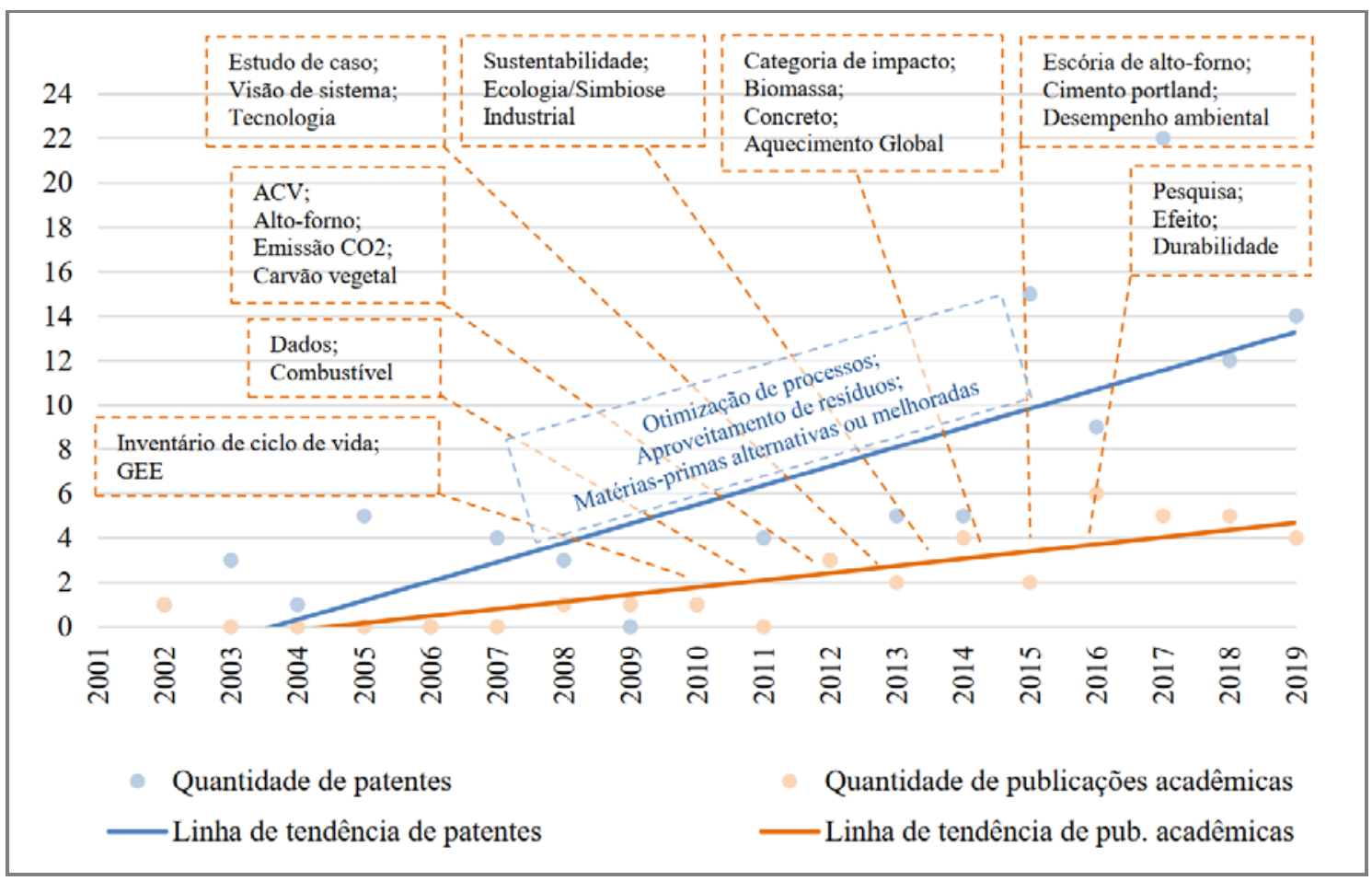

Figura 15. Tendência das contribuições acadêmicas e patentes.

De posse das evidências levantadas nas seções anteriores, a Figura 16 apresenta uma sumarização quantitativa das contribuições nos âmbitos acadêmico e tecnológico dos principais atores por região/país do globo. A contagem de patentes não levou em consideração a quantidade de reivindicações. 


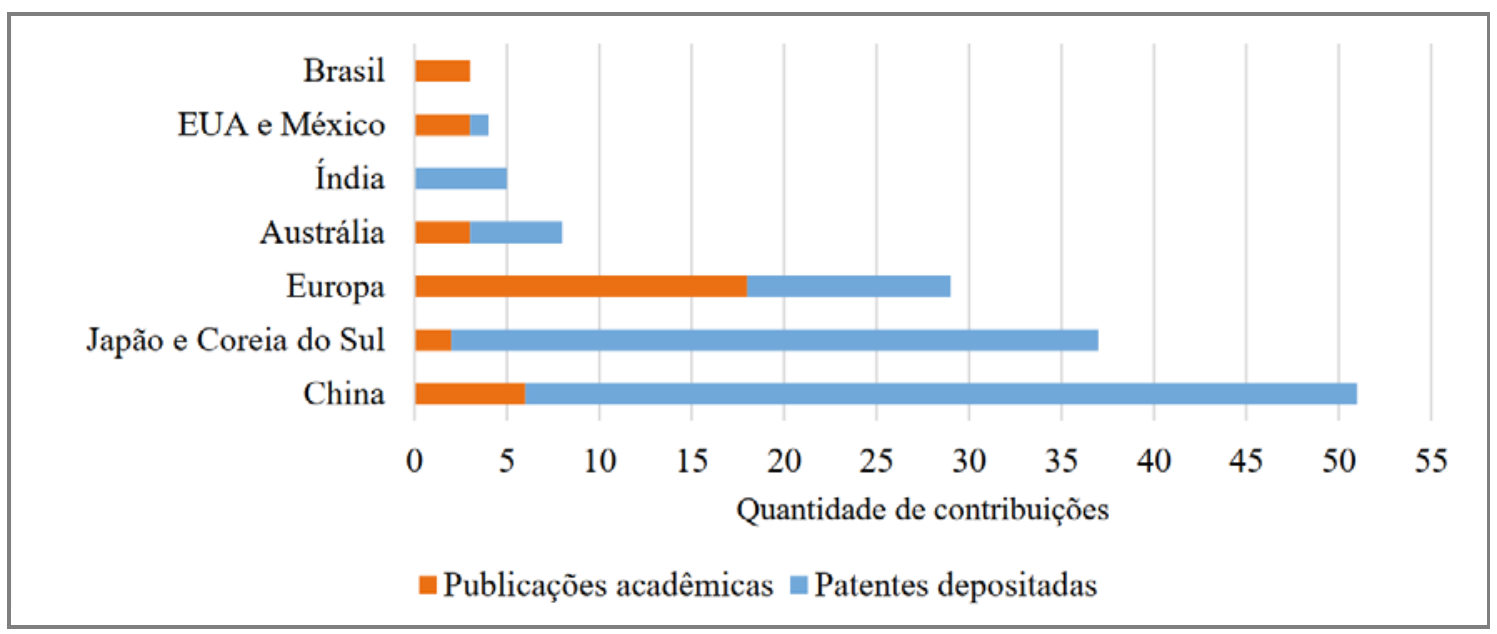

Figura 16. Contribuições acadêmicas e patentes por região/país. [renumerar no outro manuscrito]

Nota-se que o Brasil tem contribuído de forma relevante em conhecimento científico, equivalente ou até superior aos demais, porém sem participação em registro de propriedade intelectual, ou seja, sem patentes concedidas até o momento. Países da América do Norte somados se diferenciam do Brasil apenas em uma patente. A índia vem em seguida com cinco registros de patente, porém nenhuma produção acadêmica.

A Austrália tem participação marcante e equilibrada - quantidade de patentes registradas ligeiramente superior à produção científica. 0 conjunto de países europeus demonstra contribuição substancial em ambos os aspectos, com maior atuação científica, destacando-se em relação às demais regiões nesse aspecto.

Japão e Coreia do Sul, apesar de pequenos em área, tem desenvolvido tecnologia e inovação de forma substancial. Já a China, sozinha, teve a maior contribuição geral, chegando a dezessete vezes a do Brasil e destacando-se em registros de patente.

\section{Considerações finais}

Esta ampla revisão sistemática possibilitou compreender o panorama geral dos desenvolvimentos científicos e tecnológicos concernentes aos impactos ambientais da siderurgia de base. Os resultados demonstraram um alinhamento evidente em conteúdo, relevância e processo evolutivo dos avanços ocorridos em diferentes perspectivas de produção de conhecimento.

No que concerne à ACV da produção de ferro gusa, verificou-se que sua aplicação como método analítico é limitada em quantidade e consistência, embora pesquisas relacionadas tenham aumentado nos últimos anos, sobretudo sobre altos-fornos. Foram encontrados estudos sobre apenas uma rota tecnológica emergente, sendo seu desempenho ambiental não comprovadamente superior ao do processo convencional em todos os cenários de acordo com os achados.

Mesmo havendo publicações acadêmicas aderentes às questões pesquisadas, não foram localizados registros de avaliações de impacto considerando uma quantidade substancial - superior a cinco - de categorias de impacto, escolhidas e justificadas de forma assertiva a fim de montar um perfil ambiental robusto voltado para siderurgia.

Do mesmo modo, não foram identificados estudos baseados na regra de categoria produto de referência para declarações ambientais na siderurgia, ou mesmo agregaram pegada de carbono e demanda acumulada de energia na análise - dois mecanismos 
relevantes de impacto ambiental no contexto vigente, intimamente relacionados com a metodologia de ACV.

Ademais, esta revisão apontou que o objeto de estudo nas condições colocadas possui lacunas científicas a serem exploradas, principalmente no que diz respeito às tecnologias alternativas emergentes e as reivindicações de eficiência ambiental superior.

\section{Agradecimentos}

Agradecemos à Empresa Brasileira de Pesquisa e Inovação Industrial (EMBRAPII) pelo apoio financeiro durante a pesquisa.

\section{Conflito de interesses}

Os autores declaram não haver conflito de interesses.

\section{Referências}

ABNT - Associação Brasileira de Normas Técnicas. NBR ISO 14040: Gestão ambiental avaliação do ciclo de vida - princípios e estrutura. Rio de Janeiro: ABNT, 2006.

Arasto, A. Techno-economic evaluation of significant $\mathrm{CO}_{2}$ emission reductions in the iron and steel industry with CCS. Finlândia: Aalto University. 2015. (Tese de doutorado.). Disponível em: <https://aaltodoc.aalto.fi/handle/123456789/18765>. Acesso em: 29 jun. 2020.

Bahadir, M. E. Analysis of the environmental effects of international outsourcing: study of the iron casting industry. Scientific Research and Essays, v. 11, n. 16, p. 160-173, 2016. https://doi.org/10.5897/SRE2016.6421

Bains, P.; Psarras, P.; Wilcox, J. $\mathrm{CO}_{2}$ capture from the industry sector. Progress in Energy and Combustion Science, v. 63, p. 146-172, 2017. https://doi.org/10.1016/ j.pecs.2017.07.001

Burchart-Korol, D. Fossil fuels consumption evaluation in blast furnace technology based on different life cycle impact assessment methods. Anais do Metal2012, 21st International Conference on Metallurgy and Materials, 2012. Disponível em: <http://metal2012.tanger.cz/files/proceedings/02/reports/137.pdf>. Acesso em: 29 jun. 2020.

Burchart-Korol, D. Life cycle assessment of steel production in Poland: A case study. Journal of Cleaner Production, v. 54, p. 235-243, 2013. https://doi.org/10.1016/ j.jclepro.2013.04.031

CGEE - Centro de Gestão e Estudos Estratégicos. Siderurgia no Brasil: 2010-2025. Brasília: CGEE, 2010. Disponível em: <https://www.cgee.org.br/documents/ 10195/734063/Siderurgia_no_Brasil__9567.pdf/893da7ee-8608-4251-adc110c2bf95b009? version=1.0>. Acesso em: 29 jun. 2020.

Chen, S.; Fu, X.; Chu, M.; Liu, Z.; Tang, J. Life cycle assessment of the comprehensive utilisation of vanadium titano-magnetite. Journal of Cleaner Production, v. 101, p. 122-128, 2015. https://doi.org/10.1016/j.jclepro.2015.03.076

Choi, H. D. Hybrid life cycle assessment of steel production with carbon capture and storage. Trondheim: Norwegian University of Science and Technology, 2013. (Dissertação de mestrado). Disponível em: <http://hdl.handle.net/11250/235312>. Acesso em: 29 jun. 2020. 
Chowdhury, J. I.; Hu, Y.; Haltas, I.; Balta-Ozkan, N.; Varga, L. Reducing industrial energy demand in the UK: A review of energy efficiency technologies and energy saving potential in selected sectors. Renewable and Sustainable Energy Reviews, v. 94, p. 1153-1178, 2018. https://doi.org/10.1016/j.rser.2018.06.040

Crossin, E. The greenhouse gas implications of using ground granulated blast furnace slag as a cement substitute. Journal of Cleaner Production, v. 95, p. 101-108, 2015. https://doi.org/10.1016/j.jclepro.2015.02.082

Ding, X.; Li, H. Environmental benefit from blast furnace gas recycling in the integrated steelworks. Anais do 2011 International Conference on Computer Distributed Control and Intelligent Environmental Monitoring, IEEE, p.2091-2095, 2011. https://doi.org/10.1109/CDCIEM.2011.427

Fick, G.; Mirgaux, O.; Neau, P.; Patisson, F. Environmental assessment of biomass options for ironmaking. Anais do Carbon Management Technology Conference, 2012. https://doi.org/10.7122/151138-MS

Fick, G.; Mirgaux, O.; Neau, P.; Patisson, F. Using biomass for pig iron production: A technical, environmental and economical assessment. Waste and Biomass Valorization, v. 5, n. 1, p. 43-55, 2014. https://doi.org/10.1007/s12649-013-9223-1

Gielen, D.; Moriguchi, Y. Environmental strategy design for the Japanese iron and steel industry. 2001. Disponível em: <https://www.gtap.agecon.purdue.edu/resources/ download/461.pdf>. Acesso em: 29 jun. 2020.

Gordon, Y.; Kumar, S.; Freislich, M.; Yaroshenko, Y. The modern technology of iron and steel production and possible ways of their development introduction. Steel in Translation, v. 45, n. 9, p. 627-634, 2015. https://doi.org/10.3103/S0967091215090077

Hasanbeigi, A.; Price, L.; Arens, M. Emerging energy-efficiency and carbon dioxide emissions-reduction technologies for the iron and steel industry. Berkeley: Lawrence Berkeley National Laboratory, 2013. (LBNL-6106E). Disponível em: <https://escholarship.org/uc/item/5sw966f9>. Acesso em: 23 jan. 2020.

IBICT - Instituto Brasileiro de Informação em Ciência e Tecnologia. Guia geral para avaliações do ciclo de vida orientações detalhadas. Brasília: IBICT, 2014. Disponível em: $\quad$ http://acv.ibict.br/wp-content/uploads/2016/01/Manual-ILCD-com-capa.pdf>. Acesso em: 23 jan. 2020.

IEPDS - International Environmental Product Declaration System. Product category rule for basic iron or steel products \& special steels, except construction steel products: Product category rules according to ISO 14025. Estocolmo: IEPDS, 2015. Disponível em: <https://www.environdec.com/PCR/Detail/?Pcr=10372>. Acesso em: 23 jan. 2020.

IIMA - International Iron Metallics Association. Pig iron: Overview. Burnham: IIMA, 2018. Disponível em: <https://www.metallics.org/pig-iron.html>. Acesso em: 23 jan. 2020.

Jahanshahi, S.; Mathieson, J. G.; Somerville, M. A.; Haque, N.; Norgate, T. E.; Deev, A.; Zulli, P. Development of low-emission integrated steelmaking process. Journal of Sustainable Metallurgy, v. 1, n. 1, p. 94-114, 2015. https://doi.org/10.1007/s40831-015-0008-6

Kuramochi, T. $\mathrm{CO}_{2}$ capture in industries and distributed systems: Possibilities and limitations. Utrecht: Utrecht University, 2011. (Tese de doutorado). Disponível em: <https://dspace.library.uu.nl/handle/1874/205115>. Acesso em: 29 jun. 2020.

Lv, W.; Sun, Z.; Su, Z. Life cycle energy consumption and greenhouse gas emissions of iron pelletizing process in China, a case study. Journal of Cleaner Production, v. 233, p. 1314-1321, 2019. https://doi.org/10.1016/j.jclepro.2019.06.180

Rev. Bras. Gest. Amb. Sustent., 2020, vol. 7, n. 16, p. 905-936. 
Ma, F.; Eneji, A. E.; Wu, Y. An evaluation of input-output value for sustainability in a Chinese Steel Production System Based on Emergy Analysis. Sustainability, v. 10, n. 12, 4749, 2018. https://doi.org/10.3390/su10124749

Miah, K. Use of waste resources in the sinter plant in ironmaking. Sheffield: University of Sheffield, 2018. (Tese de doutorado). Disponível em: <http://etheses.whiterose.ac.uk/id/ eprint/21560>. Acesso em: 29 jun. 2020.

MME - Ministério de Minas e Energia. Anuário estatístico do setor metalúrgico. Brasília: MME, 2018. Disponível em: <http://www.mme.gov.br/documents/1138775/1732813/ ANUÁRIO+METALÚRGICO+2018.pdf/442af830-a9c6-4e75-bbc9-fef4b0f81300>. Acesso em: 23 jan. 2020.

Mousa, E.; Wang, C.; Riesbeck, J.; Larsson, M. Biomass applications in iron and steel industry: An overview of challenges and opportunities. Renewable and Sustainable Energy Reviews, v. 65, p. 1247-1266, 2016. https://doi.org/10.1016/j.rser.2016.07.061

Norgate, T.; Langberg, D. Environmental and economic aspects of charcoal use in steelmaking. ISIJ international, v. 49, n. 4, p. 587-595, 2009. https://doi.org/10.2355/ isijinternational.49.587

Olmez, G. M.; Dilek, F. B.; Karanfil, T.; Yetis, U. The environmental impacts of iron and steel industry: A life cycle assessment study. Journal of Cleaner Production, v. 130, p. 195-201, 2016. https://doi.org/10.1016/j.jclepro.2015.09.139

Pan, H.; Zhang, X.; Wu, J.; Zhang, Y.; Lin, L.; Yang, G.; Deng, S.; Li, L.; Yu, X.; Qi, H.; Peng, H. Sustainability evaluation of a steel production system in China based on emergy. Journal of Cleaner Production, v. 112, p. 1498-1509, 2016. https://doi.org/10.1016/ j.jclepro.2015.05.019

Ramos, C. G. Drivers and barriers to industrial energy efficiency and climate change mitigation in Mexico: The case of the iron and steel industry. East Anglia: University of East Anglia, 2011. (Tese de doutorado). Disponível em: <https://ueaeprints.uea.ac.uk/id/ eprint/32708/1/2011CastilloRamosGPhD-4.pdf>. Acesso em: 29 jun. 2020.

Reuter, M. A.; Van Schaik, A.; Gediga, J. Simulation-based design for resource efficiency of metal production and recycling systems: Cases-copper production and recycling, e-waste (LED lamps) and nickel pig iron. The International Journal of Life Cycle Assessment, v. 20, n. 5, p. 671-693, 2015. https://doi.org/10.1007/s11367-015-0860-4

Rojas-Cardenas, J. C.; Hasanbeigi, A.; Sheinbaum-Pardo, C.; Price, L. Energy efficiency in the Mexican iron and steel industry from an international perspective. Journal of Cleaner Production, v. 158, p. 335-348, 2017. https://doi.org/10.1016/j.jclepro.2017.04.092

Ryman, C. On the use of process integration methods: Evaluation of energy and $\mathrm{CO}_{2}$ emission strategies in blast furnace ironmaking and oxygen steelmaking. Luleå: Luleå University of Technology. 2007. (Tese de doutorado). Disponível em: <https://www.divaportal.org/smash/record.jsf?pid=diva2:999079\&dswid=-4349>. Acesso em: 29 jun. 2020.

Saade, M. R. M. Influência da alocação de impactos na indústria siderúrgica sobre a avaliação de ciclo de vida de cimentos. Campinas: UNICAMP, 2013. (Dissertação de mestrado). Disponível em: <http://repositorio.unicamp.br/handle/REPOSIP/258517>. Acesso em: 29 jun. 2020. 
Saade, M. R. M.; Silva, M. G.; Gomes, V. Appropriateness of environmental impact distribution methods to model blast furnace slag recycling in cement making. Resources, Conservation and Recycling, v. 99, p. 40-47, 2015. https://doi.org/10.1016/ j.resconrec.2015.03.011

Sablowski, A. R. M. Balanço de materiais na gestão ambiental da cadeia produtiva do carvão vegetal para produção de ferro gusa em Minas Gerais. Brasília: Universidade de Brasília, 2008. (Tese de doutorado). Disponível em: <https://ri.ufs.br/handle/ riufs/811>. Acesso em: 29 jun. 2020.

Shatokha, V. Trends and factors of sustainable development: Best available and breakthrough. In: Shatokha, V.; Stalinskiy, D.; Coole, T.; De Lepeleer, G.; Karpash, M.; Kruhlenko, L.; Petrenko, A.; Saey, P.; Shvets, I. Environmentally sustainable industrial development. Dnipro: Hetes, 2017. p. 140-164. Disponível em: <http://hetes.com.ua/wpcontent/uploads/2017/10/common_book_HETES.pdf>. Acesso em: 29 jun. 2020.

Shatokha, V.; Tymoshenko, S.; Semenko, S. Trends and factors of sustainable development: Iron and steelmaking. In: Shatokha, V.; Stalinskiy, D.; Coole, T.; De Lepeleer, G.; Karpash, M.; Kruhlenko, L.; Petrenko, X. A.; Saey, P.; Shvets, I. Environmentally sustainable industrial development. Dnipro: Hetes, 2017. p. 56-78. Disponível em: <http://hetes.com.ua/wp-content/uploads/2017/10/common_book_HETES.pdf>. Acesso em: 29 jun. 2020.

Smil, V. Modern ironmaking and steelmaking: Furnaces, processes, and casting. In: Smil, V. Still the Iron Age: Iron and steel in the Modern World. Amsterdam: Elsevier, 2016. p. 87-114. https://doi.org/10.1016/B978-0-12-804233-5.00005-1

Suopajärvi, H.; Pongrácz, E.; Fabritius, T. Bioreducer use in Finnish blast furnace ironmaking: Analysis of $\mathrm{CO}_{2}$ emission reduction potential and mitigation cost. Applied Energy, v. 124, p. 82-93, 2014. https://doi.org/10.1016/j.apenergy.2014.03.008

Suopajärvi, H.; Kemppainen, A.; Haapakangas, J.; Fabritius, T. Extensive review of the opportunities to use biomass-based fuels in iron and steelmaking processes. Journal of Cleaner Production, v. 148, p. 709-734, 2017. https://doi.org/10.1016/j.jclepro. 2017.02.029

Suopajärvi, H.; Umeki, K.; Mousa, E.; Hedayati, A.; Romar, H.; Kemppainen, A. Chuan, W.; Aekjuthon, P.; Sari, T.; Nicklas, N.; Alf, A.; Marcus, Ö.; Ulla, L.; Timo, F. Use of biomass in integrated steelmaking: Status quo, future needs and comparison to other low- $\mathrm{CO}_{2}$ steel production technologies. Applied Energy, v. 213, p. 384-407, 2018. https://doi.org/ 10.1016/j.apenergy.2018.01.060

Vadenbo, C. O.; Boesch, M. E.; Hellweg, S. Life cycle assessment model for the use of alternative resources in ironmaking. Journal of Industrial Ecology, v. 17, n. 3, p. 363-374, 2013. https://doi.org/10.1111/j.1530-9290.2012.00543.x

Wickboldt, L. A.; Moreira, J. D. A. P.; Silva, M. D. R. D.; Araújo, J. D. S.; Silva, J. V. D.; Pereira, J. A. Responsabilidade ambiental ou greenwash: uma análise da evidenciação ambiental das maiores empresas brasileiras. Revista Brasileira de Gestão Ambiental e Sustentabilidade, v. 5, n. 11, p. 897-910, 2018. https://doi.org/10.21438/rbgas.051108

WSA - World Steel Association. Steel statistical yearbook 2018. Bruxelas: World Steel Association. 2018. Disponível em: <https://www.worldsteel.org/en/dam/jcr:e5a8eda54b46-4892-856b-00908b5ab492/SSY_2018.pdf>. Acesso em: 23 jan. 2020. 
Wu, J.; Wang, R.; Pu, G.; Qi, H. Integrated assessment of exergy, energy and carbon dioxide emissions in an iron and steel industrial network. Applied Energy, v. 183, p. 430-444, 2016. https://doi.org/10.1016/j.apenergy.2016.08.192

(CC) Attribution, que permite uso irrestrito, distribuição e reprodução em qualquer meio, desde que a obra original seja devidamente citada. 